Dossier Anthropology on Latin America and the Caribbean today: New Theoretical and Methodological Challenges

\title{
Antropologías en el extremo sur: Del silenciamiento al estallido
}

\author{
Francisca Márquez' \\ 'Departamento de Antropología, Universidad Alberto Hurtado, Chile
}

\section{Resumen}

A partir de la revisión del quehacer de antropólogos/as en Chile se reflexiona sobre las derivas disciplinares a lo largo de su historia, las dificultades y desafíos para constituirse en una Antropología crítica y comprometida con la diversidad y la alteridad. Se plantea que aun cuando la Antropología sufre su desmantelamiento durante los años de dictadura, a partir del estallido social del 18 de octubre 2019 el quehacer de la disciplina gana en reflexividad, visibilidad y posicionamiento crítico. El texto se organiza en torno a los principales nudos temáticos que han acompañado a nuestra disciplina: memoria y subalternidad; gente de la tierra; feminismo y disidencias; heterotopias en el patrimonio; ecología. Se concluye con los desafíos para la consolidación de una antropología crítica y comprometida con los procesos de transformación de nuestras culturas: la cuestión de la autonomía; el compromiso con lo público; la alteridad crítica; los saberes otros; la indisciplina de la transdisciplina; la cosmopolítica de la poética.

Palabras clave: antropología, etnografía, movimiento social, neoliberalismo, Chile. 


\section{Antropologias no extremo sul: Do silenciamento à eclosão}

\section{Resumo}

Com base na revisão dos trabalhos dos antropólogos no Chile, reflete-se sobre as derivas disciplinares ao longo de sua história, as dificuldades e os desafios para se tornar uma Antropologia crítica comprometida com a diversidade e a alteridade. Propõe-se que mesmo quando a Antropologia sofre seu desmonte durante os anos da ditadura, a partir da eclosão social de 18 de outubro de 2019, o trabalho da disciplina ganha em reflexividade, visibilidade e posicionamento crítico. $O$ texto está organizado em torno dos principais núcleos temáticos que acompanharam nossa disciplina: memória e subalternidade; Pessoas da Terra; feminismo e dissidência; heterotopias na herança; ecologia. Conclui com os desafios para a consolidação de uma antropologia crítica comprometida com os processos de transformação de nossas culturas: a questão da autonomia; compromisso com o público; alteridade crítica; outro conhecimento; a indisciplina da transdisciplina; a cosmopolítica da poética.

Palavras-chave: antropologia, etnografia, movimento social, neoliberalismo, Chile.

\section{Anthropologies in the extreme south: From silencing to outburst}

\section{Summary}

Based on the review of the work of anthropologists in Chile, this article propose to reflect on the disciplinary drifts throughout its history, the difficulties and challenges to become a critical Anthropology committed to diversity and otherness. It is proposed that even when Anthropology suffers its dismantling during the dictatorship years, as of the social outbreak of October 18, 2019, the work of the discipline gains in reflexivity, visibility, and critical positioning. The text is organized around the main thematic knots that have accompanied our discipline: memory and subalternity; People of the Earth; feminism and dissent; heterotopias in heritage; ecology. It concludes with the challenges for the consolidation of a critical anthropology committed to the transformation processes of our cultures: the question of autonomy; commitment to the public; critical otherness; other knowledge; the indiscipline of transdiscipline; the cosmopolitics of poetics.

Keywords: Anthropology, ethnography, social movement, neoliberalism, Chile. 


\title{
Antropologías en el extremo sur: Del silenciamiento al estallido
}

\author{
Francisca Márquez
}

\section{Introducción}

A partir de la revisión del quehacer de los y las antropólogos/as en Chile, este artículo se interroga sobre las derivas disciplinares, las dificultades y desafíos para constituirse en una Antropología crítica y comprometida con la diversidad y la otredad. Las antropologías hechas en Chile, como todas las ciencias, portan las marcas de la historia, de la geopolítica y de las epistemes que las vieron nacer. Y así como ocurre con las Antropologías en Latinoamérica, la Antropología en Chile participa activamente en el debate de los procesos que dieron forma al estado nación, a la república, a las ciudadanías y sus identidades. En este sentido, los conceptos y métodos de la Antropología responden a la preocupación por comprender la diversidad cultural, búsqueda conceptual siempre abierta y atravesada por polémicas teóricas, prácticas y políticas. Sin embargo, la antropología hecha en Chile ha tenido discontinuidades significativas en el quehacer crítico y aplicado de la disciplina. En efecto, quiebres del contexto político y social que han dificultado que el otro y los Otros en tanto sujetos de conocimiento, hayan podido ser comprendidos como conciudadanos en los procesos de construcción social, política e intelectual (Krotz, 1993; Restrepo, 2012).

Tras la revuelta social gatillada el 18 de octubre del 2019, la disciplina y el quehacer de los antropólogos/as sin embargo, ganan en reflexividad, visibilidad y posicionamiento crítico. Las devastadoras evidencias de la crisis del malestar social, la violencia de la protesta (de allí el término de "estallido social”) y la vertiginosidad de las transformaciones sociales exigidas remecen el quehacer de antropólogos y antropólogas. La etnografía como quehacer y enfoque adquiere vigencia y visibilidad por su capacidad comprensiva en un acontecimiento que, por su vorágine y magnitud, exigen del extrañamiento y la observación directa en el terreno del paisaje de la protesta (Caldeira, 2015). En tiempos de revuelta y confusión, la etnografía se vuelve un ejercicio de inmersión en la urgencia, de esfuerzo por desandar posiciones fijadas, y por sobre todo de control del miedo para atreverse a mirar. Todo indica que el profundo sentimiento de injusticia social exige de transformaciones sociales igualmente profundas.

La tardía aparición de esta disciplina en Chile se explica en parte, por la tendencia intelectual y política de observar y proponer la homogeneidad de la población chilena como una fortaleza y virtud del Estado (Espinoza, 2014; Pavez, 2015). De allí el carácter folklorizante y conservador de los orígenes de la Antropología en nuestro país. Alejada de los críticos y complejos debates de países como México, Perú o Brasil, la Antropología en Chile nace a comienzos del siglo XX con un claro sello evolucionista, estableciéndose un cierto menosprecio acerca de los indígenas y las sociedades prehispánicas. Importante es señalar que históricamente la antropología en Chile nace de la mano de conceptos y teorías generadas en Europa y Estados Unidos; pero no escapa a la construcción de categorías analíticas que se desprenden de problemas continentales. A pesar de los esfuerzos pioneros de personajes como Gusinde, Latcham, Lenz, Guevara y tantos otros por rescatar los fragmentos de culturas condenadas a desaparecer, no será sino hasta fines de los años cincuenta del siglo XX que las ideas del indigenismo mexicano llegan a través de Alejandro Lipschutz; las teorías de la Antropología norteamericana, a través de Louis C. Faron; la Antropología francesa con Alfred Metraux y Joseph Emperaire (Márquez y Skewes, 2018; Pavez, 2015; Espinoza, 2014). 
A mediados de la década de los sesenta cuando la Antropología ingresa a las universidades ${ }^{1}$, se inicia la Antropología académica y se abren nuevos campos y objetos de estudio, como la Antropología urbana, la Etnomusicología o la Antropología física. A fines de los años sesenta los conceptos y preguntas sobre la realidad nacional permitieron desarrollar una epistemología y una perspectiva cercana a la teoría de la marginalidad (Vekemans y Silva, 1970), la dependencia y la investigación-acción participativa. Sin embargo, a partir del golpe militar de 1973 y la dictadura instalada durante 17 años en Chile, esta antropología crítica es profundamente mermada y desmantelada prolongándose las consecuencias de este despojo hasta las primeras décadas del siglo XXI. Si alguna antropología crítica se fraguaba en esas décadas, ello terminará abruptamente con el cierre de escuelas como la de la Universidad Católica de Temuco y de la Universidad de Concepción. Sólo sobrevive la Universidad de Chile, con una serie de interrupciones temporales². Aun así, y a pesar del exilio de muchos antropólogos/as ${ }^{3}$, en Chile continua un quehacer más silencioso, clandestino y con escasa interlocución con otras antropologías latinoamericanas. Al alero de organismos no gubernamentales se trabaja en una antropología aplicada comprometida con los olvidados, los sin voz, para la resistencia, solidaridad, autoconstrucción y compromiso con el oprimido (Márquez y Skewes, 2018; Pavez, 2015).

La llegada de la democracia permite el retorno de muchos antropólogos, y también la salida de jóvenes a iniciar sus estudios de pregrado. Con ello nuevas discusiones se imponen, predominando los marcos conceptuales anglófonos y francófonos. Y aunque el quehacer de la antropología chilena se diversifica temáticamente, su visibilidad en el debate público es escasa. Desperdigadas en la profesionalización de la disciplina y la mercantilización del saber al interior de las universidades, las miradas y quehaceres tienden a perder riqueza en la comprensión de los estragos de un sistema neoliberal que se inmiscuye en cada uno de los resquicios de la vida cotidiana. Iniciada la década de los noventa, nacen nuevas universidades y escuelas de Antropología ${ }^{4}$. Con este proceso de masificación de la enseñanza de la Antropología, se consolida la profesionalización de la actividad y los antropólogos comienzan a ser demandados en servicios públicos, consultoras y empresas privadas ${ }^{5}$ para estudios de impacto ambiental, así como del patrimonio nacional y la cultura. Dicha participación no ha estado exenta de debates en torno a las consecuencias éticas y políticas de estos estudios e intervenciones (Skewes, 2004). Carente de un código ético y de facultades legales para aplicarlo, el Colegio de Antropólogos ha tenido dificultades para velar por el cumplimiento de dichos principios y la protección de los pueblos afectados.

\footnotetext{
1 Primero será la Universidad de Concepción y a fines de esa década, la Universidad de Chile.

2 Tras el 11 de septiembre de 1973, el único Departamento de Antropología que sobrevive en el país, es el de la Universidad de Chile fuertemente asociado a la Arqueología, disciplina a la que el gobierno militar no considera tan crítica como otras ciencias sociales. En cambio, la situación de los departamentos de Antropología de la Universidad de Concepción y Universidad de Temuco fue dramática, del mismo modo como lo fue en la Universidad del Norte.

3 Entre quienes debieron exiliarse se cuentan Edgardo Garbulsky (1941-2007), antropólogo argentino; Milan Stuchlik (1932-1980), antropólogo y lingüista checoslovaco; Verónica Cereceda y Gabriel Martínez, antropólogos chilenos.

4 En 1984 se crea la carrera de Antropología en la Universidad Austral de Chile; en 1991, en la Universidad Católica de Temuco; en 1992 se abre en la Universidad Academia de Humanismo Cristiano; el mismo año en la Universidad Bolivariana (se cierra el 2010); el año 2005 en la Universidad de Concepción y en la Universidad de Tarapacá; el 2007 en la Universidad de Arte y Ciencias Sociales - ARCIS (se cierra el 2014); el 2011, en la Universidad Alberto Hurtado, y el 2013 en la P. Universidad Católica de Chile.

5 Hoy los campos son: la docencia en universidades e institutos profesionales; la investigación con fondos del Consejo Nacional de Investigación en Ciencias y Tecnología (CONICYT) y el Fondo Nacional de Investigación Científica y Tecnológica (FONDECYT); Reparticiones públicas como el Consejo de Monumentos Nacionales (CMN), Ministerio de la Cultura, Dirección de Bibliotecas, Archivos y Museos (DIBAM), Corporación Nacional de Desarrollo Indígena (CONADI), el Ministerio de Justicia, en sus secciones de Gendarmería; Servicio Nacional de Menores; Ministerio de Desarrollo Social; Ministerio de Educación; Ministerio de Salud en programas de salud intercultural; Ministerio del Interior, organizaciones no gubernamentales y municipios; consultorías y estudios de impacto para la Comisión Nacional del Medio Ambiente CONAMA y empresas.
} 
Imagen 1: Mural en Plaza Dignidad, Santiago: “El peor cáncer es la desigualdad”. "Revolución \$̧ilena!”.

"Somos el pueblo". "Ni derecha, ni izquierda"

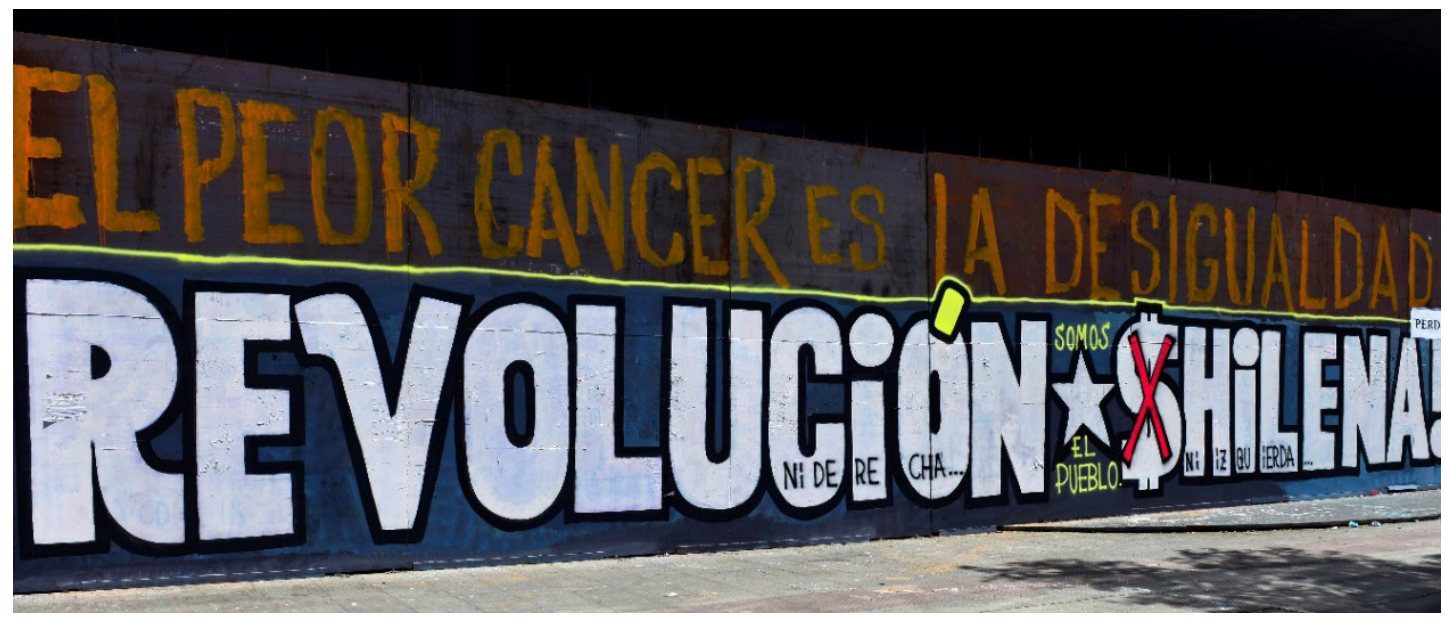

Fotografía de Álvaro Hoppe, 2020. Fondecyt 1180352

\section{Del estallido y la etnografía}

La tarde del 6 de octubre del 2019, los primeros indicios del estallido social se dejaban sentir en Santiago. Ese día, jóvenes estudiantes desafiaban a los usuarios del transporte público a "evadir” y no pagar sus pasajes de metro. A los pocos días, la desobediencia civil se transformaba en una revuelta social sin precedente contra las políticas neoliberales y la desigualdad en Chile. No era la primera vez que los jóvenes se movilizaban. Sin embargo, esta vez, las demandas parecían adquirir una envergadura inusitada en el cuestionamiento a la legitimidad del lucro en asuntos públicos y de bien común como la educación o el transporte. La rapidez con la que se expande la revuelta expresaba así una subjetividad colectiva cansada de la desigualdad y del abuso del sistema económico y político ${ }^{6}$. Sorprendido con el estallido de las manifestaciones, el presidente Sebastián Piñera declaraba que "estamos en guerra contra un enemigo poderoso" (CNN, 2019); y la primera dama Cecilia Morel los definía como "alienígenas". Desafortunadas declaraciones que se sumaban a otras como la del ministro de economía, J. A. Fontaine, que luego de aumentado el precio del pasaje de metro ${ }^{7}$, invitaba a sus usuarios a "levantarse de madrugada" para tomarlo en horario de menor precio; o la descalificación de la senadora de extrema derecha, UDI, Jacqueline Van Rysselberge, acerca que "cualquier "patipelao" se siente con el derecho a insultar a alguien que trabaja en el servicio público". Esto como reacción a los cuestionamientos a los altos sueldos (dieta) de los parlamentarios chilenos. Frente a las provocaciones de la elite gubernamental la demanda por dignidad estallará: “¿Y el pueblo dónde está? ¡Aquí en las calles pidiendo dignidad!

La Plaza Baquedano, epicentro de la ciudad de Santiago, se transforma desde ese 18 de octubre en el eje de la revuelta, allí convergen los cuerpos de miles de jóvenes para expresar su descontento y su ira. Ahora renombrada como Plaza Dignidad, "hasta que la dignidad se haga costumbre", la plaza se llena de escombros y polvo. Sus esculturas y monumento sufrirán el ritual de la antropofagia y se cubrirán de rayados y lienzo, volviéndose cada día irreconocibles en su colorido y forma. A medida que la represión policial se intensifica, esténciles y afiches con las caras de jóvenes mutilados, torturados y asesinados plasman un pizarrón de la cotidianeidad

6 La desigualdad imperante se expresa en que el 1\% de la población de Chile se queda con el 26,5\% de los ingresos y el 50\% de los hogares de menores ingresos accede solo al 2,1\% de ellos. (Cepal, 2017) A ello se suma el abuso y la corrupción que operan con toda impunidad. En efecto, entre 1996 y el 2019, la elusión y corrupción de empresas e instituciones le costó al Servicio de Impuestos Internos una pérdida de U\$ 4.982 millones (Ruiz-Tagle, 2019).

7 La tarifa del Metro de Santiago, empresa privada en cuya propiedad participa el Estado chileno, aumentó en 30 pesos el precio del ticket en "hora punta", llegando a \$ 830 pesos (US\$1,2). En Chile el costo de realizar cincuenta viajes mensuales en hora punta, en metro, equivale al 13,78\% de un sueldo mínimo, mientras en Buenos Aires equivale al 5,71\% o en Medellín al 12,64\% (González y Márquez, 2019). 
de la protesta y sus cicatrices (Candau y Hameau, 2004). Los carteles que los manifestantes llevan en sus pechos y pegan en los muros hablan de historias de abuso en sus familias, sus barrios y poblaciones. Son historias de desposesiones ${ }^{8}$ que vienen como herencia de las biografías de sus padres y abuelos. Los manifestantes no cesarán de denunciar los modos de exclusión que organizan la nación: la explotación, la pobreza, el machismo, la homofobia, el racismo y la militarización. Al poder destituyente de esta experiencia colectiva, sin embargo, la policía responde disparando a los ojos y a los cuerpos9.

Aun así, un año después, el 25 de octubre del 2020 se llevó a cabo el Plebiscito Nacional en torno a la consulta para redactar una nueva constitución para el país. La opción Apruebo (por la redacción de una nueva constitución) resultó vencedora con el 78,26 \% de los sufragios en detrimento de la alternativa Rechazo, que obtuvo el $21,73 \%$ de las preferencias ciudadanas. En cuanto al organismo que elaborará la nueva carta magna, la opción Convención Constitucional, integrada por 155 ciudadanos de los cuales 17 son representantes de pueblos originarios, resultó vencedora con el $78,99 \% .^{10}$

Una semana después del estallido, desde el norte al sur del país, profesores e investigadores, expresan su solidaridad con el movimiento social y el rechazo a la violenta represión ${ }^{11}$. Una semana después del 18 de octubre, el Directorio Nacional del Colegio de Antropólogos y Antropólogas de Chile A.G. con sede en las ciudades de Santiago, Temuco y Puerto Montt emiten una extensa declaración en la que se respalda "las iniciativas y acciones pacíficas y no violentas por parte de la sociedad civil, los movimientos sociales y la ciudadanía en general, que han tenido como objetivo central las justas reivindicaciones del pueblo chileno hacia una mayor justicia e igualdad económica social y política que haga respetar los derechos humanos y la dignidad de todos los habitante de nuestro país." Y se convoca a hacer "una antropología que permita, entre otros haberes, ayudar a hacer visibles las distintas formas de ver y estar en el mundo, que hoy están siendo oprimidas por una ideología neoliberal, que fragmenta, divide y opone a la población. Sin duda, el momento que estamos viviendo es generoso para observar las prácticas y formas de abuso, de precarización y de atropello de los derechos humanos, de criminalización de la pobreza, de gentrificación y marginalización urbana, de la corrupción que se han observado en los últimos tiempos." A casi un mes del estallido el Grupo de Estudios de Antropología y Arqueología de Fondecyt - CONICYT, anuncia la suspensión de sus actividades y emite una declaración en la que se adhiere "al movimiento social activo desplegado en todo el territorio nacional. Compartimos las agendas pacíficas y diálogos constructivos que demandan derechos sociales básicos, un país más justo y una nueva Constitución, que entre otros aspectos reconozca la conformación plurinacional de Chile." A continuación, se señala que "la política de ciencia que se elabora desde el Ministerio debe escuchar las demandas del movimiento social. Asimismo, es preciso evaluar la constitución de sus consejos y órganos deliberativos con el propósito de asegurar la participación ciudadana, la equidad de género, la articulación intersectorial amplia, el equilibrio territorial y la diversidad disciplinaria que se practica en el país. Políticas e instrumentos deben fomentar el papel de las ciencias, artes, humanidades y tecnologías en la construcción social de la nación, promoviendo la reflexión crítica, la valoración de las identidades y su convivencia,

\footnotetext{
8 Somos desposeídos por otros, señalan Butler y Athanasiou "cuando los poderes normativos inclinan la balanza de la distribución de libertades: desplazamiento, pobreza, racismo, misoginia, homofobia, violencia” (2017: 75).

9 De acuerdo con el Instituto Nacional de Derechos Humanos -INDH y la Oficina del Alto Comisionado para los Derechos Humanos - ONU (2020), las movilizaciones dejaron, entre el 18 octubre 2019 al 30 enero 2020, 3.702 personas heridas de las cuales 650 corresponden a heridas oculares, 37 muertos, más de 40 mil detenciones, más de 6 oo querellas por tortura.

$10 \mathrm{El}$ 50,86 por ciento del padrón electoral (7,5 millones de personas) asistió a los lugares de votación. La alternativa Convención Mixta Constitucional (integrada en la mitad de su composición por parlamentarios) recibió solo el 21,01 \% de los sufragios.

11 En los tres primeros meses del estallido social se contabilizan 12 declaraciones públicas del gremio de los antropólogos (Colegio de Antropólogos, 2019); 30 columnas en medios de prensa; 10 entrevistas en televisión y radio; y más de 120 etnografías y análisis en páginas web, facebook y blog. Desde las preocupaciones disciplinares se advierte de la legitimidad del reclamo social y de la urgencia del respeto a los derechos humanos de quienes se manifiestan.
} 
además de las diversas formas de conocimientos. Sus resultados deben favorecer el compromiso con una agenda y práctica de sostenibilidad, y contribuir a la superación de las profundas inequidades y las nefastas formas de antropocentrismo."

A estas declaraciones y cartas abiertas se suman cientos de textos, ensayos y columnas que nacen de estas andanzas del 'estar ahî. Son las etnografías del sur que anuncian y denuncian: anuncian (y celebran) las prácticas de esa diferencia radical desplegada en las calles, como diría Marisol de la Cadena (2015); pero también denuncian la política de control y represión a dichas prácticas. De cierta manera, así como la cultura "despertó" de su letargo, las etnografías retoman el compromiso con el análisis crítico de las estructuras de poderes y saberes que subyacen a un modelo social instalado hace casi medio siglo. Enfrentados a una sociedad diversa, desigual y enrabiada frente al abuso sistemático, el desafío se volvió simultáneamente ético e intelectual. Una mirada disciplinar atenta no solo en la enunciación de lo observado, sino también en la denuncia de la violencia y la violación a los derechos humanos por parte de fuerzas del orden.

Para los y las antropólogos/as, la afirmación de los medios de comunicación y las élites políticas, en el sentido que "nadie vio venir el estallido social" se constituyó en una clara provocación. Las investigaciones y escritos en torno a la desigualdad y el malestar social en el marco de una sociedad neoliberal abundan desde mediados de los años noventa. Las investigaciones de los noventa ya advertían como la desigualdad afecta la vida de los pueblos originarios, las mujeres, las disidencias sexuales, los pobladores urbanos, los campesinos y pescadores, entre muchos otros (Sadler y Acuña, 2003; Cancino y Morales, 2003; Gundermann y González, 2009; Pérez, 2018). Sin embargo, lo que es cierto, es que en su mayoría dichos estudios tuvieron poca o nula presencia en el debate público, quedando restringido en su circulación a los circuitos académicos ${ }^{12}$. Un año antes (2018) cientos de cientistas sociales habían denunciado que las condiciones de producción del conocimiento científico y universitario no estaban respondiendo a las urgencias de una cultura de la desigualdad producto de la mercantilización de su productividad y de adecuación a los rankings internacionales a los que se someten todas las universidades chilenas.

A partir de estas evidencias, sin embargo, el propio quehacer y categorías de comprensión se vieron remecidas. La pregunta por el propio lugar desde donde observar las grietas de nuestras culturas contribuyeron a tener que desplazar la mirada. Aunque es muy temprano para poder extraer conclusiones certeras, lo cierto es que el extrañamiento reflexivo de la Antropología pos -estallido ha contribuido también a ensayar nuevos e impensados encuadres para sustituir al otro por una nueva cromática del nosotros (porque todos somos parte activa del problema). Ya no se trata de empatía o solidaridad, sino de descubrir ese otro que habita en cada uno para así poder comprender y dialogar con las múltiples tramas del poder que condicionan el quehacer de las Antropologías. De ahí, como nos advierten Guizardi y Gonzálvez (2021), el especial cuidado epistemológico que se impone frente a las categorías analíticas empleadas. Un cuidado que no se explica solo por las evidencias de la interseccionalidad de la exclusión y subalternidad, sino también porque quienes escriben son también parte de ese problema. De allí que "los debates se vuelvan enunciados desde una posición que molesta la estabilidad de la bipolaridad analítica entre sujetos y objetos de estudio" (2021), dejando paso a un pensamiento antropológico, parafraseando libremente a Gramsci (2013), que no puede sino ser una experiencia eminentemente política.

El texto que aquí se presenta, se construye desde este recorrido por la genealogía de los saberes y autores/ as de la disciplina y la pregunta por sus huellas, quiebres y vigencia en el debate presente. El texto se organiza en torno a algunos de los principales nudos temáticos que han acompañado a nuestra disciplina:

12 Algo similar se advierte para México, Giglia, Garma y de Teresa (2007:140): “La antropología ha dicho mucho y aún tiene mucho qué decir [...], el problema es que en las últimas décadas hemos participado muy poco en la esfera pública y hemos dejado que otros, desde periodistas hasta críticos literarios, ocupen nuestros lugares de antaño.” 
memoria y derechos subalternos; gente de la tierra, silenciamiento y guerra; feminismo y disidencias; heterotopias en el patrimonio; ecología. Se concluye con los desafíos para la construcción y consolidación de una antropología crítica y comprometida con los violentos e incesantes procesos de transformación de nuestras culturas.

Imagen 2: Monumento expresidente Balmaceda. Se lee: Resistencia. Nunca Más. Gracias por devolver la esperanza

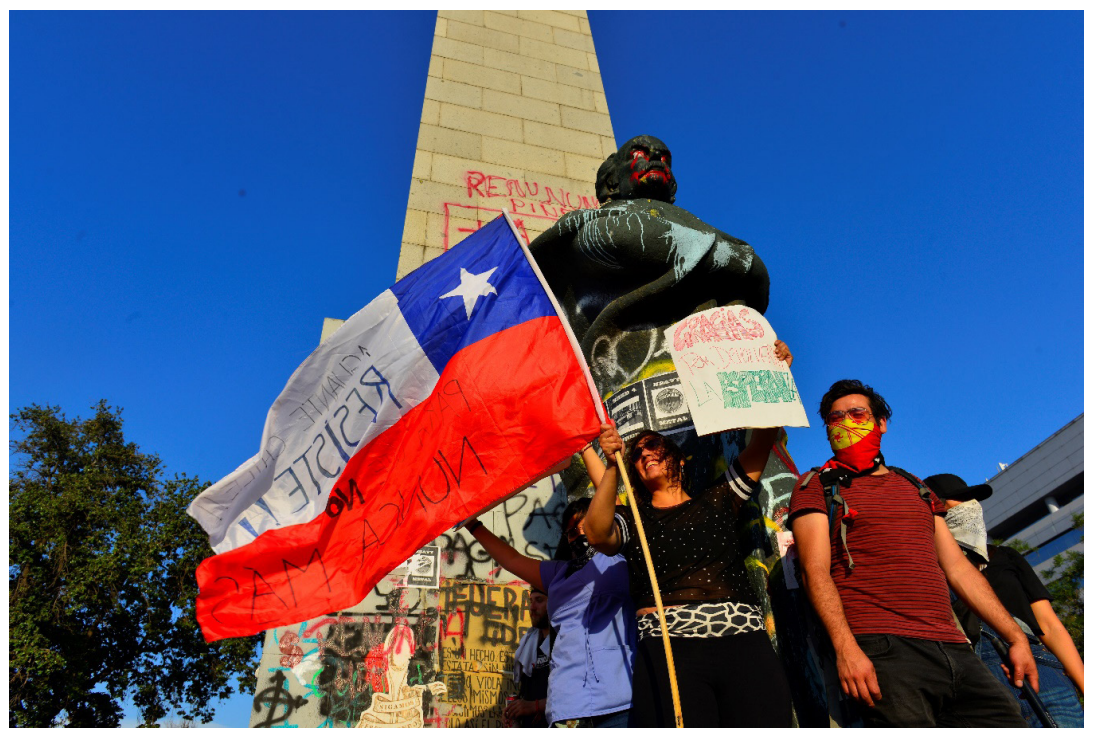

Foto: Alvaro Hoppe, 2019

\section{De memorias, desigualdades y derechos subalternos}

¿Qué impulsó la sublevación en Chile? Difícil era imaginar un estallido y una revuelta con tanta ira como la de la sociedad chilena. Desde ese día, la pregunta por las causas profundas del estallido social recorre la mayoría de los escritos de antropólogos/as en Chile. La mayor parte reconoce en este malestar y en esta ira las huellas del neoliberalismo y la democracia autoritaria que se ha perpetuado desde los tiempos de la dictadura (Palma y Piña, 2019). Una ira y un malestar soterrado que al estallar deja entrever una memoria plagada de excesos y desigualdades largamente incubados y soportados por generaciones. La crítica al sistema capitalista permea la mayor parte de los análisis; la mercantilización de cada uno de los aspectos de la vida, parece ser la constante que hace pensar en una desmesura de las exigencias a las que se somete a cada individuo en nuestras sociedades de mercado. Crítica a la ontología capitalista que reduce incluso la naturaleza a un medio de producción, haciendo de la quimera de la igualdad de oportunidades una posibilidad inalcanzable para la gran mayoría. La lucha por los derechos a la vivienda, a la salud, al transporte, a las pensiones dignas, a la educación; el derecho a la vida digna ha emergido como el urgente horizonte político. En este contexto la dignidad o la vida digna como categoría moral se cubren de significado político desde donde increpar y a la vez volverse sujetos éticos (Pérez, 2018).

A estas urgentes cuestiones se suma la preocupación por la violación sistemática de los derechos humanos de los manifestantes durante el estallido social, reactualizando resabios de una etnografía forense ${ }^{13}$ que pondrá a la arqueología a trabajar codo a codo con la etnografía (Armstrong et al., 2020). Sin embargo, el camino de visibilizar las contranarrativas no es simpley asílo atestiguan los relatos etnográficosy declaratorias disciplinares.

13 El origen de la Antropología forense debe buscarse con Juan Munizaga (1974 - 1981 fundador de la Antropología física. Bajo el liderazgo de Isabel Reveco la Antropología Forense juega un rol crucial en el esclarecimiento del destino de detenidos desaparecidos durante los años noventa. El esfuerzo pionero de este grupo no estuvo exento de problemas en la identificación de las víctimas de la dictadura debido a los precarios procesos formativos durante las décadas anteriores. 
En estas contranarrativas, el/la antropólogo/a habla también como ciudadano, movilizado y militante. El "estar ahî" de la observación participante es más que nunca, una mirada histórica, cultural y políticamente situada. De allí que la mayor parte de los escritos producidos durante estos meses sean redactados en primera persona: yo estuve ahí, puedo atestiguar. Primera persona que a su vez permite también testificar en un contexto que se hace desde el colectivo y de las escrituras múltiples, y donde las paredes parecen ser el dispositivo privilegiado frente a la desinformación y la confusión que instalan los medios de comunicación.

Esta diversidad de contextos de producción de saberes nos deja en evidencia también, que el ethos del científico social siempre tendrá que vérselas con otros ethos y otras éticas. Pensar el modo en que el saber de la Antropología pueda hoy conectarse con la diversidad social pasa por atravesar los límites de su saber, multiplicando los vínculos con los saberes en movimiento: de los movimientos estudiantiles, de los movimientos indígenas, de los pescadores artesanales, de los mineros, de los movimientos de vecinos, de los jóvenes olvidados, de la diversidad sexual, de las disidencias y de todos estos saberes y memorias otras que exigen el derecho a un lugar en las decisiones para una nueva constitución. Lo cierto es que tras el estallido social, se hace evidente la urgencia no solo de investigar y acompañar a "los otros de la propia nación", especialmente indígenas y sectores subalternos, acercándose a las antropologías del Sur o segundas (Krotz, 2008). Sino que, se hace más explícita la tensión epistemológica, política y ética de cómo conocer a ese otro que no es distante, sino cercano y asimismo, cómo lograr la convivencia con ese otro cercano. Sumergidos todos y todas en el paisaje de la protesta para hacer frente a un sistema neoliberal y abusivo (Valenzuela, 2019), las fronteras con estos otros de la propia nación se hacen más difusos y porosos.

Por otra parte, se hace especialmente evidente que los migrantes o los indígenas no son diferentes sólo por su condición étnica, sino también porque la reestructuración neoliberal de los mercados agrava su desigualdad y exclusión. El problema de la relación entre diferencia y desigualdad plantea que es necesario ir más allá del "giro cultural" predominante en la antropología. No se trata de sustituir el "determinismo culturalista" por un renovado "determinismo economicista", sino buscar una nueva síntesis que considere las diversas dimensiones de la desigualdad (Reygadas apud Giglia et al., 2007). A partir de lo señalado, la diversidad y la desigualdad del país se hace evidente, y adquiere urgencia el proyecto de los derechos universales y el combate a la exclusión mediante políticas de igualdad interculturales. Tras el estallido, tal como nos recuerda Esteban Krotz (2018), resultará difícil desligar la idea de una Antropologías del Sur de la protesta incansable contra la desigualdad.

Imagen 3: Grafitis y carteles durante el estallido social: No es bueno hacerse de enemigos que no estén a la altura del conflicto; Pensión Digna, Evade, Salgan a la calle

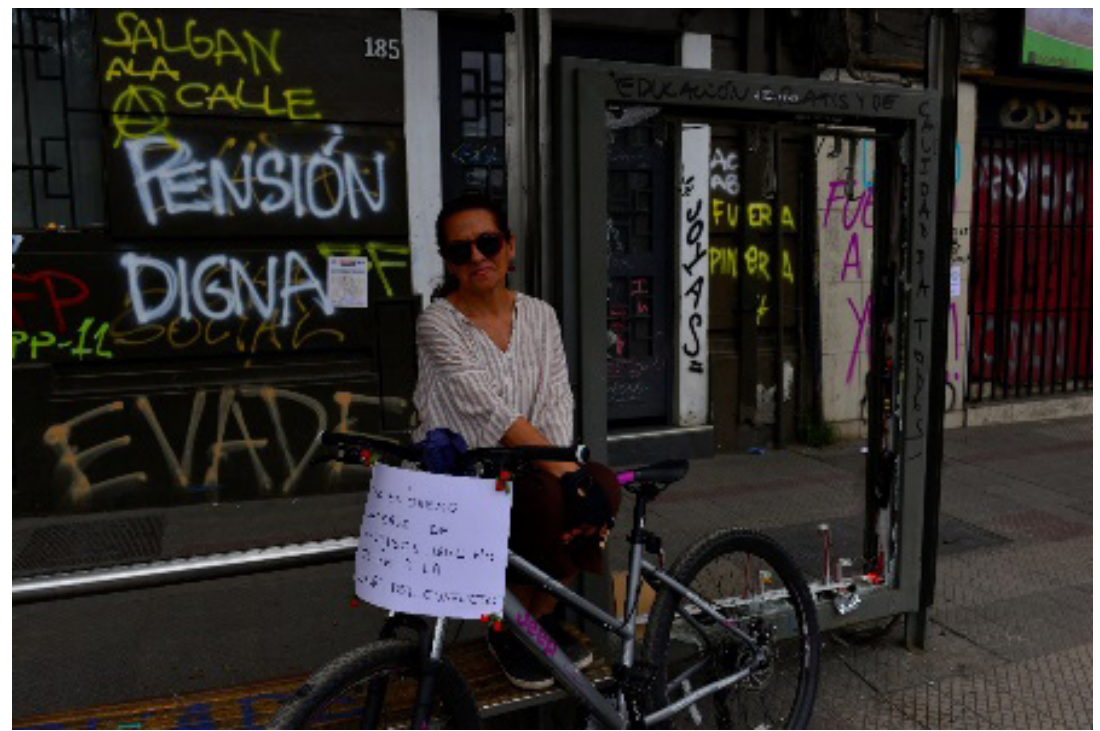

Foto: Alvaro Hoppe, 2019 


\section{Gente de la tierra, silenciamiento y guerra}

La vocación centralista y autoritaria del Estado chileno, difícilmente puede ser comprendida sin la incesante guerra en el sur fronterizo y las políticas de silenciamiento y blanqueamiento de la asimilación a los pueblos indígenas. En efecto, desde las primeras descripciones del pueblo mapuche ("gente de la tierra" en lengua mapudungún), por cronistas laicos y eclesiásticos en el período colonial o los primeros estudios sistemáticos desde fines del siglo XIX, la perspectiva dominante ha sido la asimilacionista, marcada por el evolucionismo. ${ }^{14}$ A lo largo de la historia republicana, nada ha cambiado. Durante el régimen militar (1973-1990), periodo en que se impulsaron iniciativas legislativas y políticas que amenazaron las tierras mapuche y su existencia como pueblo, los estudios indígenas se circunscribieron al campo del folclore, la cultura campesina y tradicional (Márquez y Skewes, 2018; Pavez, 2015; Espinoza, 2014).

Tal como nos advierte Restrepo (2020), la administración de la diferencia por parte del estado-nación es de gran relevancia para comprender la configuración de los estilos antropológicos. Las "formaciones nacionales de alteridad" se tejen de la mano de la producción histórica de "los otros de la nación" (Briones, 2008; Segato, 2007). En Chile, sólo reestablecida la democracia (1990) la Antropología política y jurídica pone en el centro del debate la revisión de las políticas y legislación asimilacionista, así como los temas de autonomía y derechos. Ello permitió que en 1993 el Congreso aprobara la llamada "Ley Indígena" ${ }^{15}$. Sin embargo, en un Estado orientado hacia el crecimiento económico y resistente a integrar las diferencias étnicas y culturales, las contradicciones en la relación con los pueblos indígenas se acrecentaron (Mariman y Aylwin, 2008, Castro, 2014). ${ }^{16}$

Ciertamente el rezago de Chile en materia de aceptación de la ciudadanía multicultural no sólo es producto de las restricciones del marco jurídico-político legado por el régimen militar (sistema binominal o elevados quorum de reforma constitucional), sino de una cultura arraigada en la clase política, de que en Chile no hay sino un solo pueblo, el chileno; de que los indígenas están desde largo tiempo integrados al país; y de que dicho reconocimiento además amenaza con fragmentar al Estado. Esa cultura asimilacionista se expresa también en la percepción de que el llamado "problema indígena" es esencialmente de carácter económico y se manifiesta en las condiciones de pobreza (Mariman y Aylwin, 2008). El carácter fuertemente centralizado del Estado chileno y la fuerza del pensamiento liberal como base del modelo económico neoliberal vigente desde tiempos de la dictadura, son factores que contribuyen a minar el terreno de la pluralidad cultural (Bello, 2003).

Paradojalmente, mientras las voces indígenas y los factores históricos que inciden en este conflicto aparecen reducidos y distorsionados, los espacios de protesta tras el 18 de octubre se han cubierto de íconos como la wephala (bandera andina) y wenufoye (bandera mapuche). Con ello pareciera expresarse el reconocimiento a la capacidad de resistencia de este pueblo, y el relevamiento de narrativas de la historia que buscan alejarse de aquellas articuladas por las élites gobernantes o grupos de poder (Le Bert y Soto, 2021).

14 El lingüista alemán Rodolfo Lenz (1863-1938), el sacerdote capuchino Félix José de Augusta (1860-1935) y el ingeniero polaco Ignacio Domeyko (1802-1889) estudian el pueblo mapuche inscribiéndose en el marco asimilacionista del Estado-nación como mecanismo para incorporarlos a la nacionalidad católica y republicana.

15 La Ley № 19.253 de Fomento, Protección y Desarrollo de los Indígenas si bien no recoge varias de las demandas centrales planteadas por sus organizaciones -tales como el reconocimiento de su carácter de pueblo y de los derechos políticos y territoriales asociados a éstos-, reconoce a las "etnias" y comunidades indígenas, sus culturas y sus tierras; se estipula el deber del Estado y la sociedad de respetarlas y protegerlas; se crea un fondo para la ampliación de sus tierras y aguas y otro para la promoción del desarrollo indígena; y se establece una Corporación Nacional de Desarrollo Indígena (Conadi) como ente gubernamental de integración bipartita, encargado de la conducción de la política pública en la materia. La legislación de 1993 generó en los pueblos indígenas expectativas de cambio en su relación con el Estado (Mariman y Aylwin, 2008).

16 Los esfuerzos desarrollados por el movimiento mapuche para lograr su reconocimiento jurídico y político y asumir el control de sus territorios ancestrales amenazados por proyectos de inversión extractivista, se han mostrado altamente infructuosos. De allí que a pesar de la vasta literatura antropológica e histórica y la adhesión que tiene la "causa mapuche" entre la ciudadanía, el ideario de una ciudadanía intercultural que incluya el reconocimiento de los pueblos indígenas y sus derechos colectivos, entre ellos la libre determinación, parecen ser horizontes difíciles de alcanzar. En el caso mapuche, frente a las estrategias de desobediencia civil, la respuesta del Estado ha sido la "criminalización” y responsabilización de "actos terroristas" contraviniendo el Código Penal y los lineamientos internacionales en la materia. 
Los 17 representantes de los pueblos reconocidos en la Ley Indígena (№ 19.253) que, gracias a la revuelta social, han sido elegidos para ocupar los escaños reservados para los pueblos indígenas en la Convención Constitucional ${ }^{17}$, abren un espacio institucional impensado hasta hace poco ${ }^{18}$.

De esta realidad hay muchas preguntas que se desprenden, entre ellas cómo recuperar territorio para los pueblos indígenas; cómo recuperar el poder de gestionar y decidir sobre ese territorio; cómo construir un quehacer político desde el reconocimiento del despojos y colonizaciones, para avanzar hacia un diálogo donde perderle el miedo a la diferencia y a la fricción (De la Cadena, 2015). En este denso debate sobre el futuro, conceptos como autonomía, autodeterminación, derechos políticos colectivos, derechos culturales y lingüísticos son necesarios para que dicho diálogo sea sustentable (Antileo, 2020). Una antropología decolonial, que rompa con la tradición de un racismo científico, evolucionista y asimilador es urgente. Una antropología que sea también aliada y cómplice para la superación de nociones asimilacionistas en pos de una matriz identitaria nacional, y que aporte en el debate para enfrentar desde la interculturalidad y la subalternidad la escritura de una nueva carta constitucional para una institucionalidad plurinacional (Alvarado, 2021).

Sin embargo, advierte el antropólogo Álvaro Bello(2016), frente a la crisis que representa la sobreinterpretación de la identidad, su esencialización y nueva racialización, lo que se requiere es una actitud crítica de la diversidad y de soluciones políticas y económicas para las sociedades multiétnicas y plurinacionales. Definitivamente los tiempos de la nación homogénea han quedado en el pasado. Sin embargo, porque la problemática de la identidad/pertenencia no puede ser vista solo como un ejercicio teórico o académico, en la medida que la cuestión de las identidades afecta la convivencia y el modo en que se organizan los Estados y las sociedades contemporáneas, la cuestión de los límites identitarios, de sus contenidos, formas y efectos son un problema político que debe resolverse en el espacio público y no solo en las aulas universitarias (Berho, 2020).

Imagen 4: Mural en homenaje a Camilo Katrillanka, asesinado por las fuerzas policiales

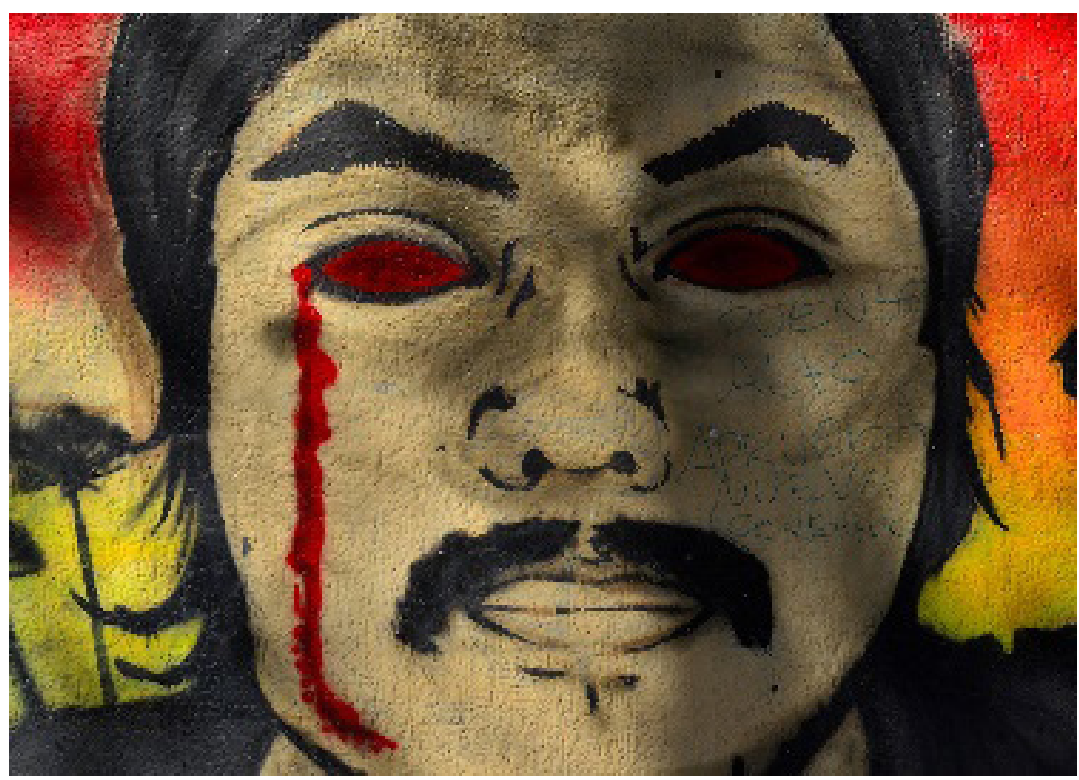

Foto: Álvaro Hoppe. 2019

17 El Servicio Electoral (Servel) reconoce siete cupos para los mapuche, dos para los aymara y uno para cada uno de los otros pueblos: rapanui, quechua, atacameños, diaguitas, collas, kawéskar, yaganes y changos.

18 Ciertamente a ello ha contribuido también la creciente presencia de intelectuales indígenas que han dotado a sus organizaciones de argumentos para fundamentar sus demandas culturales, políticas y territoriales. La joven constituyente mapuche Natividad Llanquileo Pilquimán, abogada, señala 4 ejes prioritarios para la nueva Constitución: Reconstruir el valor de lo diversos y plurinacional; Una nueva relación con la naturaleza; El fortalecimiento y ampliación de derechos; Un país digno y sostenible para más y mejor democracia. 


\section{Feminismo y disidencias}

En Chile, el movimiento feminista irrumpió a partir del año 2015, con las marchas \#Ni una menos y \#8M, retomando así prácticas que remitían a las movilizaciones de los años ochenta contra la dictadura. Tal como ocurre en América Latina, las demandas del movimiento feminista han estado asociadas históricamente al derecho a ser reconocidas como iguales y a la participación política y laboral en igualdad de condiciones. No obstante, en la última década, la agenda feminista suma a estas demandas históricas, la necesidad de remunerar el trabajo reproductivo, doméstico y de cuidados, el acceso a una educación no sexista, así como la garantía de lugares de trabajo y estudio seguros y libres de acoso o abuso y la despenalización del aborto (Urzúa, 2019; Calquin y Gonzálvez, 2018). En términos generales es evidente que la crítica feminista ha contribuido a puntualizar el carácter situado del conocimiento, la íntima relación entre saber y poder, en definitiva ha colocado a las grandes narrativas en el contexto de la política (Rebolledo, 2014). Pero en términos de la vida social, el feminismo ha tenido logros importantes como la creación de normativas que prohíben el acoso callejero, la elaboración de protocolos que sancionan el abuso sexual dentro y fuera de los centros educativos, la promoción de una educación no sexista, el reconocimiento institucional del nombre social de personas transgénero, la ley proaborto en tres causales, la paridad de género en la Convención Constituyente constituyen los primeros (e insuficientes) pasos de un largo camino por visibilizar prácticas de abuso naturalizadas y alcanzar la plena igualdad de derechos entre mujeres y hombres.

Paradojalmente, el siglo XXI se caracteriza por el aumento de las violencias hacia el género femenino y hacia las identidades definidas al margen del patriarcado (gays, lesbianas, queers, bisexuales, indefinidos/ as) (Segato, 2016). La radicalización de la violencia multidimensional se revela especialmente grave en el caso de las mujeres migrantes que optan por una vida transfronteriza. Esta realidad explica por qué las reflexiones sobre género y también movilidades son una urgencia en la agenda de investigación (Guizardi, Gonzálvez y Stefoni, 2018).

Tras el estallido social en Chile, la presencia de actos corporalizados se multiplicaron en los espacios públicos como una manera de (de)enunciar la violencia de género en cada uno de los aspectos de la vida. La mundialmente masiva performance de LasTesis sintetiza, quizás como ninguna otra performance, la ira y el dolor que produce dicha violencia. Mujeres con los ojos vendados y formadas en filas, con movimientos rudos que asemejan la marcha militar, acusan con sus gritos "el violador eres tú"; para luego afirmar con voz firme, “y la culpa no era mía, ni dónde estaba, ni cómo vestía”. Cuentan las creadoras de esta performance, que se inspiraron en la antropóloga Rita Segato (2016) para escribir la letra de la canción. En ella se acusa y denuncia al patriarcado y al Estado por la impunidad del feminicidio y la brutal victimización de las mujeres frente a la violencia ejercida sobre sus cuerpos de manera sistemática e institucionalizada. ${ }^{19}$ Pero no fue la única performance, durante los cinco meses de la revuelta, las calles se poblaron de danzas y gestos que visibilizaron la profundidad de las injusticias de las mujeres y por cierto de las disidencias sexuales (Osorio, 2021). Las consignas vuelven una y otra vez, a la denuncia de la violencia: “¿Y cómo es la wea? ¡Nos matan y nos violan y nadie hace na;"; "Arder, arder, arder, al macho feminicida queremos ver arder". En estos ejercicios performativos de los cuerpos femeninos que se aglomeran sobre avenidas, plazas y monumentos, el gesto político transmite experiencia y conocimiento vital, pero sobre todo reclama el propio lugar en la historia (Taylor, 2015). En lo efímero del baile, del cuerpo desnudo, de los pechos ensangrentados (Arellano, 2019), de los ojos mutilados,

19 La letra dice: El patriarcado es un juez, que nos juzga por nacer y nuestro castigo es la violencia que no ves. El patriarcado es un juez, que nos juzga por nacer y nuestro castigo es la violencia que ya ves. /Es feminicidio/ Impunidad para el asesino/ Es la desaparición/ Es la violación/Y la culpa no era mía, ni dónde estaba, ni cómo vestía Y la culpa no era mía, ni dónde estaba, ni cómo vestía / El violador eras tú El violador eres tú Son los pacos (policías) Los jueces El estado El presidente El estado opresor es un macho violador/ Duerme tranquila niña inocente, sin preocuparte del bandolero, que por tus sueños dulce y sonriente vela tu amante carabinero. El violador eres tú. 
se expresa el acto y el gesto político en el campo de la protesta. Tal como nos advierte Diana Taylor, son estos los gestos que nos enseñan que la cultura no es algo petrificado en el papel ni en la escritura, sino arena de disputa social y lucha por el derecho a estar ahí. Lo relevante, para este momento de nuestro quehacer como etnógrafos/as es que en estos meses de protesta todos estamos en escena, todos los actores participamos en simultáneo y entrelazados en este drama para la representación colectiva, aunque solo sea para molestar y hacer tambalear los marcos sociales de la memoria (Halbwachs, 2004).

Por lo pronto, el movimiento comienza a mostrar sus primeros triunfos y la antropología feminista se abre a esta creación de mundos y órdenes diversos; sabiendo que todo régimen de verdad está siempre conectado a regímenes de poder. De allí que para analizar el lugar del conocimiento científico en esta escena, la antropología feminista reconozca la importancia de explicitar la propia condición colonial. ${ }^{20}$ Hablar de epistemologías feministas desde el sur es también una invitación a preguntarse no sólo de que modo las ciencia hegemónica ha desplazado con violencia los conocimientos locales acerca del cuerpo y la naturaleza o los saberes ancestrales, sino que también de que modo esta división ha permitido que el cuerpo de las mujeres y sujetos subalternos sean usados desposeídos y mercantilizados (Calquin y Gonzálvez, 2018). De allí la importancia para esta epistemología feminista, de avanzar hacia el desarrollo de relatos que rompan con la hegemonía discursiva que impone un único mundo posible y una sola forma de leerlo. El camino es largo, y exige partir por develar las relaciones de poder y lugares de enunciación heteropatriarcales que desde lugares diversos sitúan y naturalizan a las mujeres en posiciones subalternas (Guizardi y Gonzálvez, 2021; Calquin y Gonzálvez, 2018; Sadler y Acuña, 2003).

Imagen 5: Marcha del 8M; se lee, somos libres; la "mujer" no tiene límites

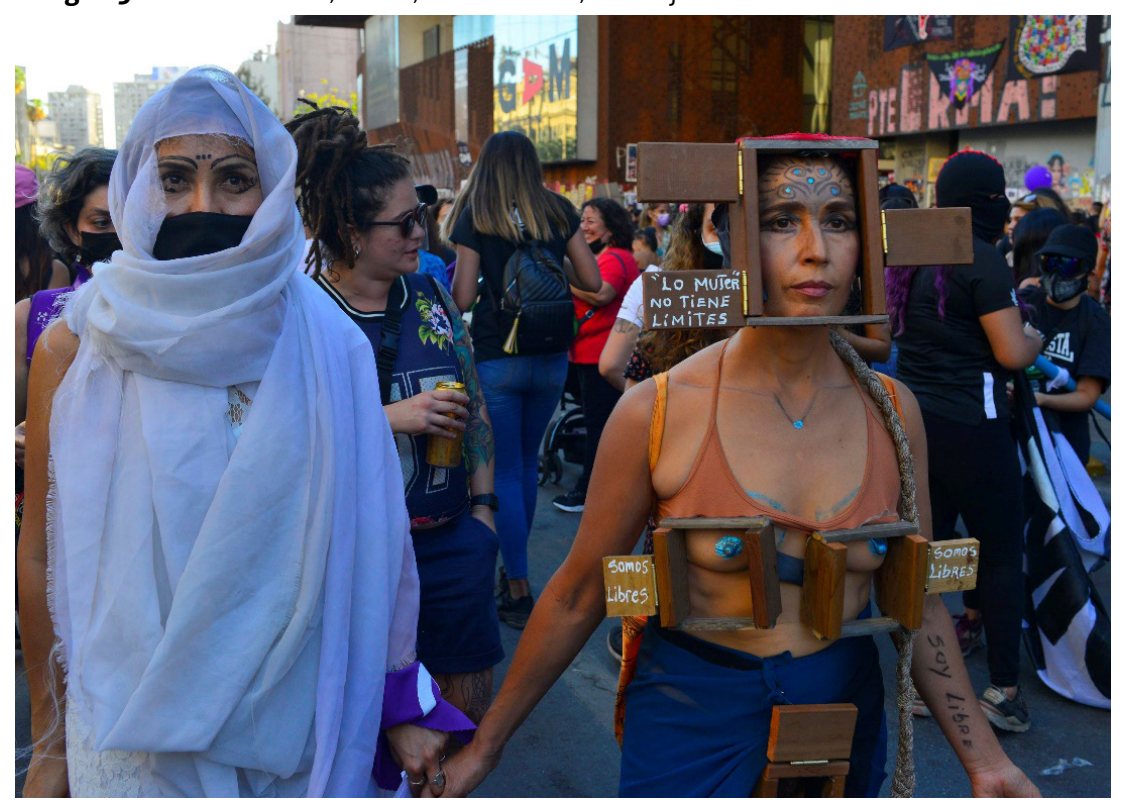

Fotografía Alvaro Hoppe, 2020

20 Las antropólogas Guizardi y Gonzálvez (2021) aluden a aquella “academia más ortodoxa” para referirse las instituciones y profesionales que reproducen desigualdades de género en el ejercicio de la investigación profesional y de la docencia universitaria. En pleno siglo XXI, los índices de desigualdad de ingreso entre hombres y mujeres en instituciones académicas son frecuentemente superiores a las medias verificadas en el mercado laboral general. 


\section{Desmonumentalización y heterotopías}

Hasta antes del estallido social, en las discusiones sobre memoria y patrimonialización, rondaba una cierta incomodidad entre quienes escribíamos y discutíamos sobre políticas y prácticas de la memoria. Hablar de memorias y patrimonio, parafraseando a Claudia Briones (2020), era atravesar campos minados. En efecto, monumentos, estatuas, mausoleos, monolitos y museos constituyen los objetos testimoniales privilegiados de aquello que la Nación y los citadinos rememoran. Y aunque históricamente, ha sido tarea del Estado y su institucionalidad la definición e instauración del corpus patrimonial a través de su materialidad arquitectónica, la antropología sabe que toda ideación e instauración de lo patrimonial, no es jamás unívoco, sino una construcción social compleja, de ideologías, prácticas y narrativas históricamente situadas y disputadas.

Sin embargo, desde fines del siglo XX, fuimos testigo del nacimiento de los monumentos "otros", monumentos incómodos producto de los hechos de violencia política y transgresión a los derechos humanos allí ocurridos. Durante la llamada postdictadura, la antropología chilena seguía atenta el llamado "giro conmemorativo" que inauguraban los memoriales a los detenidos, torturados y desaparecidos durante las décadas de dictadura. Memoriales que abrían la posibilidad de una relectura a las narrativas hegemónicas de la monumentalidad patrimonial y que nos recordaban que el relato de la nación se hace también de dolorosa subalternidad (López, 2020; Bustamante, 2016).

A partir del estallido social, en Chile como en tantas otras partes del mundo, a este giro conmemorativo se sumarán otros, pero esta vez para remitirnos a rituales antropofágicos y gestas contramonumentales. Con el descabezamiento de Pedro de Valdivia y su cabeza colgada de la mano de Caupolicán, el monumento desaparecido de José Martí, la proliferación de banderas wipala y wenufoye como expresiones simbólicas del pueblo andino y mapuche (Campos y De la Maza, 2019) y la creación del museo a cielo abierto del Colectivo Originario en el centro de Plaza Dignidad, se inaugura la transgresión y desmonumentalización de las figuras icónicas del colonialismo español, republicano y patriarcal, pero también una masiva e insurrecta contramonumentalización. Enfrentados al patrimonio patrio derruido, nuevos sentidos, discusiones y posibilidades se imponen. También para la Antropología y la Arqueología que no tardarán en escudriñar estos desplazamientos de la materialidad resignificada (Armstrong et al., 2020; Márquez, Colimil, Jara, Landeros, Martínez, 2020; Lindskoug et al., 2020).

Es evidente que la fuerza y la violencia depositada en los procesos desmonumentalizadores en la plaza pública no se juega en que los ciudadanos sepan con certeza quiénes son los personajes cuyas estatuas asaltan ni tampoco cuáles hechos los hacen merecedores de ser esculpidos, forjados $\mathrm{y}$, ahora, derribados. Lo que está claro es que estamos frente a gestos de profunda connotación política, gestos que increpan la res publica y sus obras emplazadas en el espacio de lo público y lo monumental. Es en esos centros históricos y urbanos donde se despliega el ethos civilizatorio del proyecto de nación. Sin embargo, es en este mismo espacio solemne de la urbanidad donde se inscriben los gestos insurrectos que dan forma al paisaje de la protesta. Son los gestos que hacen frente a la poética del poder excluyente para desmontar los aparentes consensos y regímenes de representación (Durán, 2021; Márquez, 2020; 2021); y para recordarnos y enseñarnos - a la manera de la pedagogía de las estatuas - que la historia, ni la más violenta, fagocita de todas las memorias y de todas las experiencias históricas. Siempre, la historia puede ser revisitada, subvertida y actualizada. Es allí, en el espacio de lo público, donde las masas en la calle oponen su propio orden del día a la agenda gubernamental, instantes aparentemente efímeros de interrupción del flujo temporal, pero donde progresivamente se instalan las transmutaciones efectivas del paisaje de lo visible, de lo decible y de lo pensable (Rancière, 2010). Energía transgresora y creadora del paisaje de la protesta, que transmuta y reordena el orden de lo urbano y por sobre todo, de la mirada de etnógrafos/as sobre la ciudad. Transformar los campos minados de lo "patrio-patrimonial" exigirá abrirse hacia las posibilidades de coexistencia intercultural que, en vez de neutralizar nuestros desacuerdos afectivos 
o morales y nuestros conflictos ontológicos, ideológicos y epistemológicos, permita explorar todo lo que está en disputa o hace fricción al momento de definir patrimonio y herencias. En definitiva, perderle el miedo a vivir en la fricción para encontrar formas de ser juntos siendo diferentes (Briones, 2020).

Imagen 6: Monumento General Baquedano y graffitis: A.C.A.B. / All caps are bastard; Libertad a los presos. Venceremos

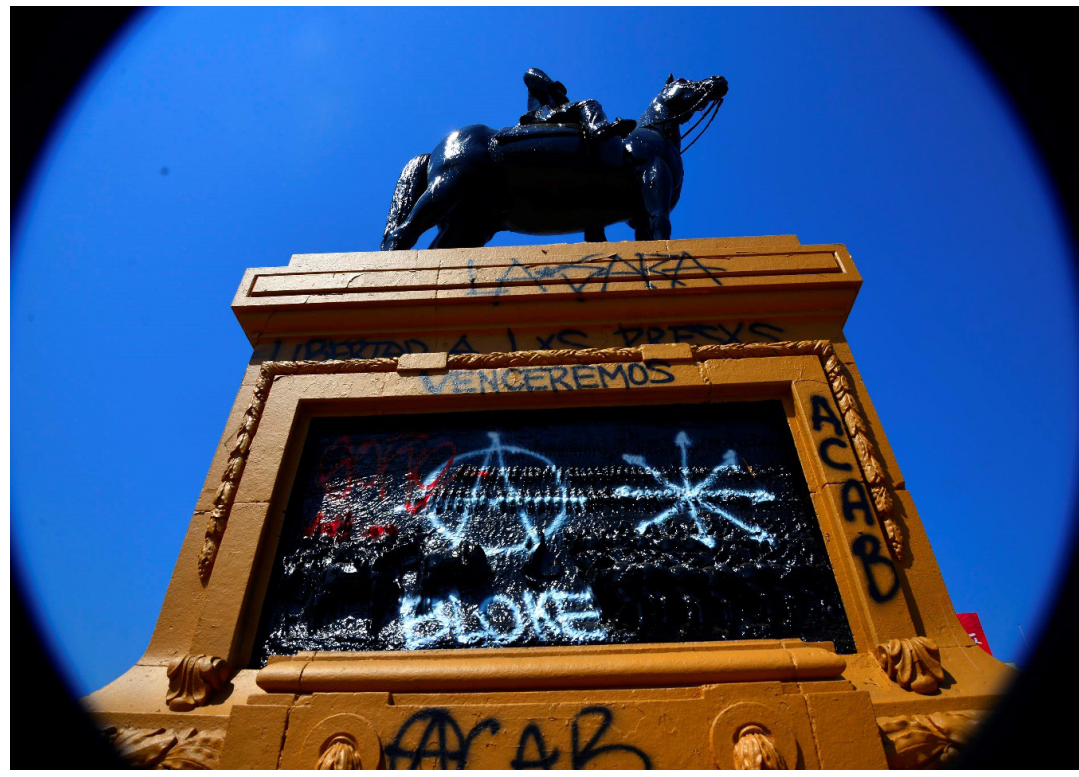

Foto: Alvaro Hoppe, 2020

\section{Del naturalismo a las urgencias del ecologismo}

Chile, así como el continente, no solo ostenta la mayor desigualdad social del planeta, sino también la mayor pérdida de biodiversidad producto de consolidación de la lógica extractivista, el cambio climático y el desorden generalizado que gobierna los fenómenos planetarios (Skewes, 2019). En esta perspectiva, más que taxonomizar o inventariar, la Antropología hoy se ve increpada a observar y analizar los saberes de las culturas en torno al medio ambiente y sus territorios, las disputas y los conflictos ecológicos obligando a hacer ciencia y política al mismo tiempo. Lo que está en juego no es solo como se entiende la relación entre los seres vivos, sino como se la quiere modelar. No es de extrañar entonces, que los interrogantes se inscriban en el marco de las urgencias antropocénicas. De allí la proliferación de estudios que sitúan la mirada sobre la naturaleza en el contexto del Antropoceno como el marco geológico en que se enmarca la supervivencia planetaria, así como la capacidad de desplegar pensamientos y acciones en un mundo en crisis (Danowski y Viveiros de Castro, 2019). Con ello se evidencia lo teórico y empíricamente problemático que resulta separar naturaleza de cultura cuando nos enfrentamos a una transformación radical del planeta. El Antropoceno no solo pone en crisis la división naturaleza y sociedad, ciencias exactas-naturales y ciencias humanas-sociales, también compromete la relación entre conocimiento experto y conocimientos locales. Contra los efectos aniquiladores que se plantean, el desafío pareciera ser multiplicar pensamientos, prácticas, formas de vivir y vincularse. En estos términos, de lo que se trata es de entrar en la complejidad del mundo -o los mundos- en el que vivimos. Esta emergencia creciente de los estudios que interrogan los conflictos socioambientales, lo no-humano, el buen vivir, la presencia de los seres-tierra (De la Cadena, 2015), se acompañan también de importantes activismos ambientales. 
En efecto, durante las manifestaciones del estallido social ${ }^{21}$, la presencia de grupos ecologistas, veganos y antiespecistas se hizo sentir. Jóvenes que desde una perspectiva ético-política y un estilo de vida contrahegemónico buscan transformar las relaciones de explotación entre animales humanos y no-humanos ${ }^{22}$. Con ello ciertamente se abre un camino para poner en cuestión el modo dominante de relación con el entorno y las fricciones que los modos de producción dejan tras de sí.

La literatura antropológica producida durante las últimas décadas da cuenta de dichos desacuerdos epistémicos u ontológicos que se producen en los relacionamientos con la industria extractiva y el crecimiento urbano sin otra regulación que las leyes del mercado. La preocupación por la agencia -la capacidad de actuaren heterogéneos ensamblados de humanos y no humanos como una cosmopolítica - una política ampliada al resto de los actantes no humanos- invita también a pensar de manera crítica y colectiva (Stengers, 2014). Pero si como señala Arturo Escobar (2015), el proyecto del mundo moderno consiste en convertir a los muchos mundos existentes en uno solo, el mundo del individuo y el mercado, habría que preguntarse cuál es el horizonte razonable que le cabe a estos estudios antropológicos en la traducción de los múltiples mundos y voces que pugnan por hacerse un lugar y ganar una voz.

Las nuevas ecologías, nos dice Skewes (2019), invitan a hacerse cargo del desorden más que procurar un nuevo orden. Ciertamente en el desconocimiento de la práctica de vida de los habitantes de los paisajes boscosos, hay un desconocimiento de la historia, de la biodiversidad y de la soberanía local (Ibarra y Riquelme, 2019). Tal vez de lo que se trata es de abandonar las perspectivas totalizadoras y englobantes como horizontes explicativos (y activistas), para poder reconocer en las comunidades las experiencias y las memorias que contribuyan a anudar conversaciones y luchas políticas para otras ontologías y otras epistemologías. Cabría preguntarse, sin embargo, si estas colaboraciones nos permitirán repensar las formas en las que humanos y no-humanos nos aliamos. Si desde la fricción y la diferencia nos abriremos a repensar la naturaleza como nuestra aliada y a relevar la creatividad de los actores locales para transitar desde una economía depredadora hacia formas protectoras de las demás especies. Las formas posibles de integrar seres humanos, árboles y demás especies exigen un contrato en un marco prospectivo de convivencialidad y de buen vivir, y entender las relaciones entre los seres humanos y los animales como un acomodo recíproco cuyos términos se definen procesualmente (De Munter, 2016). Una ontología relacional exige ciertamente, pasar desde una condición residual a otra protagónica y sin espacios de soberanía no se ve transitable el sendero, señala Skewes (2019). Advertencia que en un país que observa como sus ríos se secan y sus bosques son devastados por el fuego y la acción humana, adquiere hoy día más que nunca, el carácter de urgencia.

\footnotetext{
21 A propósito del estallido social y el ícono del Matapacos, el antropólogo J.C. Skewes y el geógrafo R. Quiroz (2020) señalan "El caminar libertario y colectivo del Negro Matapacos encarna el reclamo más intenso de las demandas populares: la dignidad [....]. La lección del Negro Matapacos exige infiltrar el corazón de una nueva constitución política donde la dignidad, esto es, la consideración que a todo ser vivo se debe, constituya su centro. En esta fábula se pone de relieve el emparentamiento de sujetos difusamente presentes o presentados en los estallidos sociales, emparentamiento que incluye personas y animales como un ejercicio de solidaridad colectiva y acompañamiento mutuo, contradiciendo el paradigma individualista de la neoliberalización o la lógica de domesticación jerarquizada que generalmente articula las relaciones entre humanos y no humanos."

22 CNNChile "Anti-especistas" atacaron laboratorio de arqueología de la U. de Chile. https://www.cnnchile.com/pais/anti-especistas-atacaron-laboratorio-de-arqueologia-de-la-u-de-chile_20171019/
} 
Imagen 7: Jardín de la Resistencia en los escombros del metro quemado. En el centro foto de Cristián Valdebenito, 48 años, muere al ser impactado por un proyectil percutado por Fuerzas Especiales de Carabineros durante una protesta

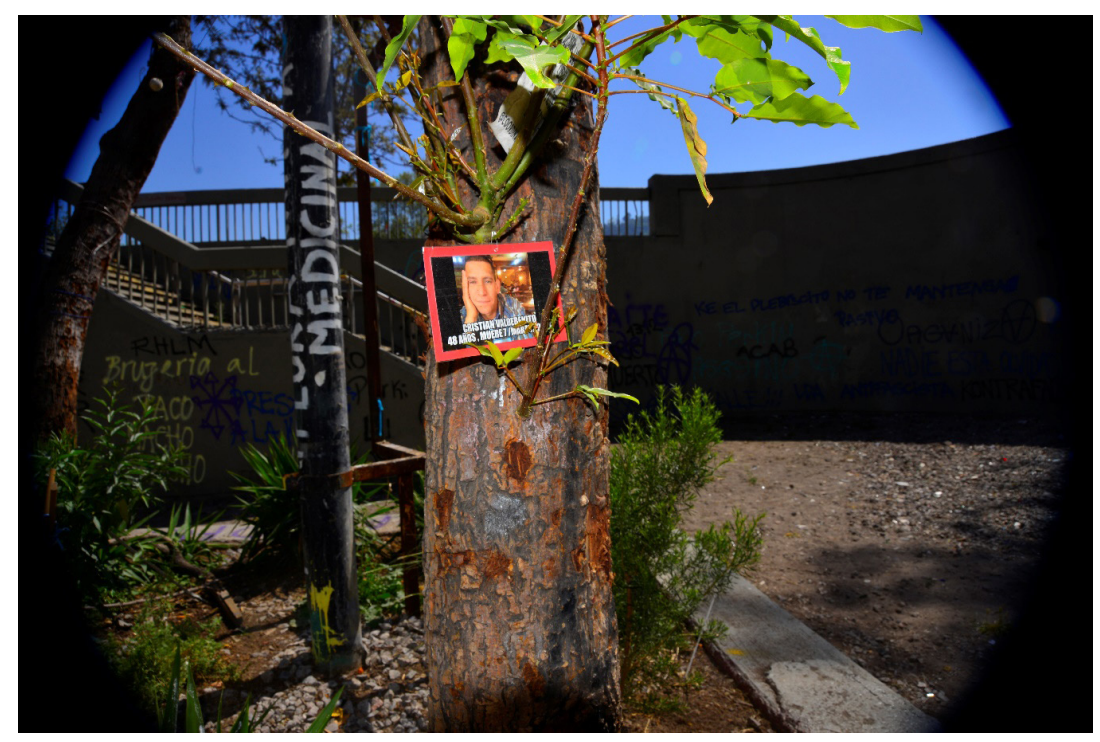

\section{Reflexiones finales}

Decía en la introducción, que la trayectoria de la Antropología en Chile no puede sustraerse de la doble paradoja que condiciona su formación disciplinar. De una parte, su asincronía con los procesos históricos y latinoamericanos; y de la otra, los profundos quiebres y silenciamientos en su vocación crítica. Ambas características la han conducido a una alta dispersión temática, inconsistencia paradigmática y debilidades en la construcción teórico-metodológica. Ciertamente, la progresiva mercantilización de los quehaceres de la Antropología tampoco ha contribuido a romper con esta tendencia. Sin embargo, en este artículo se propone, a modo de hipótesis de trabajo que, a pesar de esos quiebres y silenciamientos, tras el estallido social de octubre del 2019 el quehacer de la disciplina vive un renacer en términos de sus definiciones epistemológicas y enfoques metodológicos. Cuatro son los ámbitos del quehacer disciplinar que están en el debate:

La cuestión de la autonomía: este es un aspecto central para una disciplina que nace de la mano de intereses coloniales, en contextos neoliberales y fuertemente mercantilizados. Autonomía ¿respecto de quéy de quiénes? La pregunta por la autonomía que hoy se pone en cuestión refiere a las relaciones de las etnografías con las instancias de decisión y significado histórico y geopolítico. En Chile, así como en otros países del sur, las estrategias económicas liberales, la globalización económica, la privatización de activos, la mercantilización de algunos sectores y el aumento del mercado como casi único principio regulador, hacen urgente la pregunta por el poder de esos agentes sobre nuestro quehacer. En el predominio del capitalismo académico, de las consultorías para el Estado o para empresas como son los estudios de impacto medioambiental, este juego de actores ha tendido a complejizarse. De allí la duda por el margen de soberanías posibles y deseables para nuestras etnografías del sur. Sabemos que ese juego de poderes puede instalar una lógica que redirecciona el quehacer de las etnografías hacia lo que permite y lo que "paga el mercado". Para un pensador (neo)liberal en economía, el mercado expresa bien las necesidades sociales a través de los precios. Más allá de la crítica a esa afirmación, hemos aprendido en este medio siglo de economía liberal que la etnografía arriesga su perspectiva crítica al someterse a los intereses e indicadores de mercado (incluso de la academia). Parte del legado de décadas de neoliberalismo que minimiza lo público y el conocimiento como un bien común, es la mercantilización de la cultura y el quehacer de la disciplina para transformarla en agentes del Estado o del empresariado. 
De allí que redibujar la geopolítica del conocimiento antropológico en los términos de Esteban Krotz, en un contexto de tanta desigualdad y mercantilización de la vida y de las ciencias del sur, exige inevitablemente priorizar el resguardo de nuestra autonomía en el quehacer de la Antropología.

El compromiso con el lenguaje de lo público: ¿Cómo devolver a nuestra democracia el derecho a la visibilidad, al reclamo, a la voz? ¿Qué significa reivindicar derechos cuando no se tiene ninguno? Judith Butler (2010) nos responde: solo traduciendo al lenguaje dominante, pero no para ratificar su poder, sino para ponerlo en evidencia y resistir a su violencia diaria. Para ello hay que encontrar el lenguaje a través del cual reivindicar los derechos a los que uno no tiene todavía derecho. En esta perspectiva parece importante insistir que una autonomía solo es posible en compromiso con lo público, por lo común, por su impacto y deber social. De allí que la autonomía "de" sea siempre una autonomía "para", sin lo cual la primera carece de valor pleno. El sentido público habla de la importancia de minimizar el riesgo de un quehacer etnográfico volcado hacia sí mismo, que no reflexiona sobre las consecuencias de su interdependencia con la cultura. Ciertamente este imperativo nos interroga respecto de la naturaleza e implicancias de nuestra producción. Una axiología profunda de las etnografías del sur sólo es posible cuando ella observa las consecuencias culturales (a veces nefastas) de su conocimiento; allí es cuando el lenguaje de lo público emana.

La alteridad crítica: Lo señalado nos lleva a la condición de una etnografía crítica, critica de sí misma y de su quehacer: ¿para qué el conocimiento?, ¿para qué investigar? Preguntas que no se responden solo en la cualidad del conocimiento mismo, sino en cuestiones que dicen relación con la democracia, el colonialismo, la diversidad, la sustentabilidad, la igualdad. Comprender y mostrar que los problemas no están sólo en las situaciones y voluntades de cada individuo, sino en violencias estructurales, simbólicas y normalizadoras de nuestras culturas desiguales, requiere con urgencia ser parte constitutiva de nuestro quehacer. Hoy, las posibilidades de autodeterminación están desigualmente distribuidas en el tejido social y una descripción de las contranarrativas no es simple, porque ello reclama romper con la naturalización de las condiciones en que se produce el conocimiento. Hoy, sin embargo, la disciplina en Chile vive un proceso de revisión crítica y reparación: La reemergencia étnica, el feminismo, las disidencias sexuales o las nuevas ecologías, son estallidos que demandan un esfuerzo de relectura de aquellas memorias contadas desde un solo lado (Segato, 2007).

Los saberes otros, saberes nuestros: Decíamos en la introducción, que en la historia de la disciplina, la división entre conocimiento científico y saberes o entre saberes autorizados y saberes prohibidos, fue radical. Mientras los primeros se recluían en el marco de las epistemologías cientificistas y de las especializaciones disciplinarias, los saberes otros han transitado fuera de los muros de las ciencias. De allí la importancia para las etnografías del sur, a) de problematizar los paradigmas de la cientificidad objetiva y desligada de la praxis del vivir; b) de avanzar hacia la transdisciplina e indisciplina; pero sobre todo c) de integrar el pensamiento académico al diálogo colectivo con los saberes otros. Esteban Krotz señalaba que la característica central de los estudios antropológicos en las zonas sur del planeta, no es investigar a unos "otros", sino a sus propias comunidades. Se trata no tanto de librarnos de una situación postcolonial, sino de llevar adelante "la tarea pendiente de la de(s)colonización" del conocimiento (Krotz, 2018).

Nelly Richard (2007) se preguntaba cómo leer el conflicto de hablas entre, por un lado, los conocimientos calificados de la especialización académica (regulares, sistemáticos, reconocidos) y, por otro, los saberes desarmados y enrabiados. Efectivamente, integrar saberes otros al diálogo y la comprensión del des-orden y el des-concierto de nuestras culturas, es parte del diálogo a construir. Hoy, en tiempos de revuelta y pandemia, esos otros saberes están delante y con modulaciones propias, en las calles, quemando monumentos, saqueando supermercados, marchando infatigables, gritando y cantando. En todos estos gestos corporalizados hay saberes otros que exigen soberanía, esto es, el derecho a un lugar en la construcción de la cultura y en la toma de decisiones. Pero pensar los conocimientos etnográficos del sur supone ante todo que atravesemos - como 
antropólogos que somos - los límites, amarrándonos y fundiéndonos en y con los saberes locales y en movimiento. Porque en estas expresiones de los grandes movimientos y revueltas que nos recorren como continente, la "agencia cultural" no es individual, sino colectiva; no es institucional ni estructurada, sino rizomática y flexible. Es el reconocimiento de esta condición la que le otorga su impronta epistemológica y política a nuestras etnografías del sur. Siguiendo las palabras de Silvia Rivera Cusicanqui (2013), diremos que es responsabilidad del quehacer de las etnografías del sur no contribuir al remozamiento de las formas de dominación y al encubrimiento de prácticas de colonización y subalternización. Solo así, las etnografías del sur son y seguirán siendo - como creo haber visto estos meses en mi país, - etnografías subalternizadas. Sólo deconstruyendo los centrismos podremos contribuir a responder ¿por qué acontece lo que nos acontece? Solo así podremos comprender ¿de qué transgresiones nos hablan los cuerpos desnudos de las jóvenes mujeres sobre los monumentos de próceres de la patria patriarcal?, ¿qué reclamos y saberes se esconden en los bailes y rituales de nuestras calles y de nuestros bosques?

Indisciplina de la transdisciplina: Si las etnografías del sur quieren volverse mundanas, de este mundo, deberán respetar que en el mundo nada está ontológicamente separado del resto. Esto nos envía a la transdisciplinariedad y a la indisciplina como formas de integrar, de comprender. En estas turbulencias, los paradigmas se pierden y el desorden puede ser una fuente de una fecundidad inagotable (Balandier, 2003). La lección de estos tiempos de revuelta es que ya no son las situaciones estables lo que interesa, sino los procesos, las crisis, las inestabilidades, lo que se transforma, las alteraciones geológicas y climáticas, la evolución de las especies, las mutaciones y crisis de las culturas que se pensaban democráticas. Lo que está en juego, citando nuevamente a Esteban Krotz, no es meramente la posibilidad de producir representaciones pulcras y certeras del mundo social, sino la posibilidad de transformarlo para mejor. Hoy más que nunca, hay una responsabilidad que nos atañe, una ética de las etnografías del sur se hace urgente para no olvidar que son otros los que ponen el cuerpo mientras nosotros observamos, pensamos y escribimos. Si aquellos a quienes se les denomina "subalternos" no participan de manera efectiva de la descolonización del conocimiento, la indisciplina epistémica desde el sur terminará siendo más un juego retórico que una alternativa política del conocimiento (Sandoval, 2021).

Finalmente, cabe señalar que, en esta conflictiva y nunca acabada construcción del orden deseado, la tarea de la Antropología pareciera ser contribuir a una ontología que se niegue a separar y a oponer objeto y sujeto (Bourdieu y Waquant, 1992). Exigencia ética para comprender como en un movimiento simultáneo, los individuos son actores condicionados socialmente, pero como siendo actores e individuos, ellos logran producir nuevas estructuras de sentidos colectivos a pesar de las estructuras que los constriñen. Una arqueología de estas experiencias y espacios políticos se impone con urgencia. No hay relato democrático posible, no hay reencantamiento posible sin este ejercicio etnográfico. Una cultura que no se interroga acerca de sí misma, que no conversa del sentido que pueda tener la convivencia actual y futura, sustrae a la política su razón de ser y renuncia a la política como esfuerzo colectivo. La construcción de la vita activa (Arendt, 2009) en dignidad, como la que hoy se reclama, exige de soportes colectivos y simbólicos que alimentan el quehacer en sociedad. Descifrar esta poética del quehacer político en los espacios públicos, constituye hoy en Chile un desafío que la Antropología no debiera descuidar.

Cosmopolítica y poética: Finalmente, en tiempos de pandemia la cercanía de saberes y experiencias subalternas adquiere especial relevancia en la construcción de nuestras sociedades. Estas discusiones incorporan no solo una perspectiva de extrañamiento reflexivo y crítico, sino también una dimensión cosmopolítica que asume los problemas contemporáneos y latinoamericanos a la luz de los desafíos políticos y culturales globales (Stengers, 2014). Desde esta dimensión cosmopolítica no interesa clausurar el lente sino abrirlo a una diversidad de filtros para capturar la riqueza de los matices y cromáticas que el colectivo nos ofrece. En esta perspectiva se piensa la multiplicidad de ensambles que hacen posible la política colectivamente para así navegar a contracorriente 
de este mundo moderno que convierte a los muchos mundos existentes en uno solo, el mundo del individuo y el mercado (Escobar, 2015). De allí las preguntas que la revuelta deja en nosotros: ¿Cómo cartografiar esos mundos provenientes de horizontes lejanos de modo que nos atrevamos a perderles el miedo?

La pregunta que parece relevante para este momento de la historia de Chile es la pregunta por aquellas densidades y constelaciones significantes que permitirán el paso de la revuelta a la sociedad que queremos. Para la Antropología chilena, la masividad de la revuelta y la violencia que la acompañan nos enrostra que la experiencia de la desigualdad y de la mercantilización de cada uno de los aspectos de la vida excede lo que como cientistas sociales previmos. Ello ciertamente nos desafía en el modo de pensar la antropología, más centrada en la producción de evidencias que de la denuncia de las desigualdades. Parafraseando a Rodolfo Walsh, la Antropología no debe olvidar que las paredes son las imprentas de los pueblos, y allí se cobija un lenguaje de muchas capas y cortezas, dejándonos abierta la puerta a lecturas múltiples y contradictorias. En estas etnografías de la revuelta, hay que admitir que todos y todas aprendimos también a ser poetas; y como tales, las dudas en la interpretación de lo sucedido proliferaron. Pero a los poetas eso no les importa, porque de eso se trata, de hacerle el quite al saber unívoco. El poeta "desmigaja" el dolor y el desconcierto, y a través de su verso forja la poética que los de la calle insurrecta no sabríamos como nombrar. Si en algún momento de la historia la sociedad chilena se pensó ordenadamente neoliberal, un oasis, la naturaleza indómita de la revuelta vino a romper y cuestionar esos imaginarios. El verso poético irrumpió para anunciar la pérdida de legitimidad de la mirada única y patriarcal; devolviéndonos la confianza en esa primera persona que narra, canta y revuelve el movimiento de una sociedad desigualmente lastimada.

Imagen 8: Jóvenes de la "primera línea” por el apruebo a la Convención Constituyente

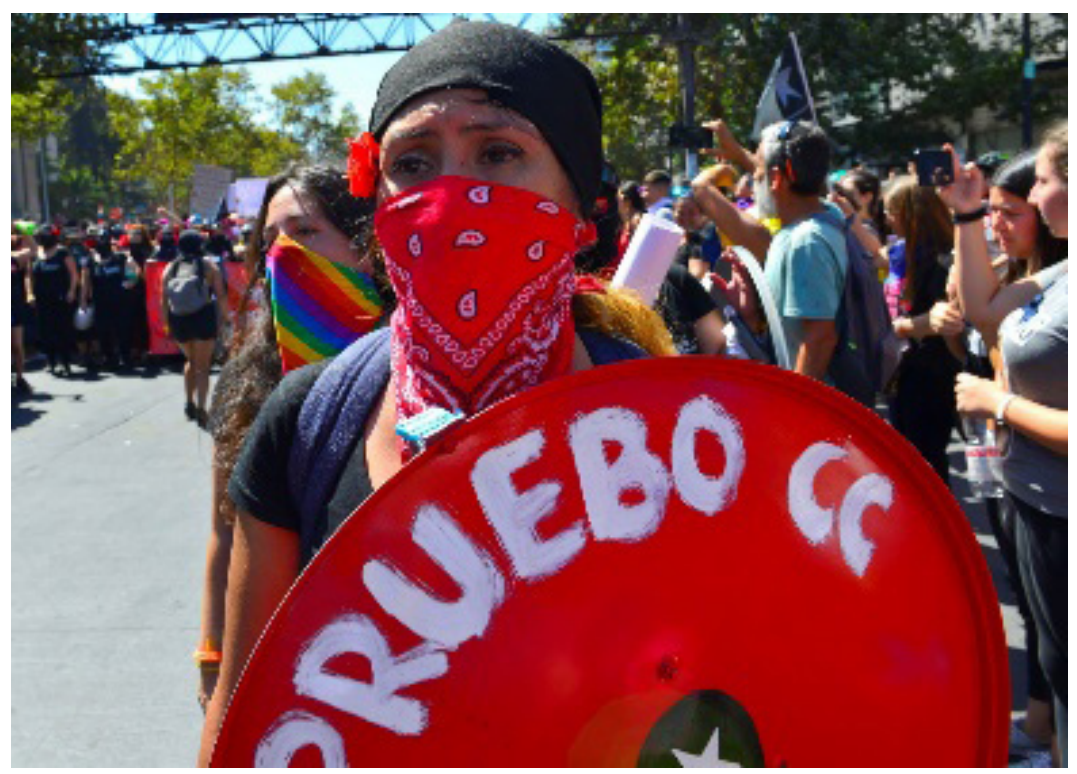

Fotografía Alvaro Hoppe, 2019

Recibido: 27 de junio de 2021

Aprobado: 18 de agosto de 2021 


\section{Referencias}

ANTILEO, Enrique. 2020. ¡Aquí estamos todavía! Santiago: Pehuen Editores.

ALVARADO, Claudio. 2021. "Es un problema político, no militar: poder mapuche, diálogos plurinacionales y Nueva Constitución”. Disponible en: https://www.ciperchile.cl/2021/03/05/es-un-problema-politico-nomilitar-poder-mapuche-dialogos-plurinacionales-y-nueva-constitucion/

ARELLANO, Claudia. 2019. "La Crisis del abandono". Pagina 19. Edición Aniversario Primer Año. Disponible en: https:/|pagina19.cl/opinion/la-crisis-del-abandono-y-revuelta-social-una-perspectiva-feminista/

ARENDT, Hannah. 2009. La Condición Humana. Buenos Aires: Ed. Paidós.

ARMSTRONG, Felipe et al. 2020. "Documento de trabajo. Guía de registro de Intervenciones Gráficas Urbanas. Grupo de estudio Arqueologías Contemporáneas del Arte y la Violencia”. Manuscrito. Depto. de Antropología, Universidad Alberto Hurtado. DOI: 10.13140/RG.2.2.25490.68804

BALANDIER, Georges. 2003. El desorden: la teoría del caos y las ciencias sociales, elogio a la fecundidad del movimiento. Barcelona: Gedisa.

BELLO, Álvaro. 2003. Etnicidad y ciudadanía en América Latina. La acción colectiva de los pueblos indígenas. Santiago de Chile: Cepal.

BELLO, Álvaro. 2016. “¿Pertenencia o identidad? Implicancias de dos categorías socioculturales para los derechos indígenas...”. Revista Antropologías del Sur, 3(6): 13-27.

BERHO, Marcelo. 2020. "Debate”. En: Gonzalo Diaz (ed.), Antropología Contemporánea. Intersecciones, encuentros y reflexiones desde el Sur Sur. Temuco: Ed. Universidad Católica de Temuco. pp. 171-173.

BOURDIEU, Pierre; WAQUANT, Loic. 1992. Résponses. París: Seuil.

BRIONES, Claudia 2020. "Interculturalidad y patrimonialización: La invisibilización de escenificaciones del ser juntos siendo otros”. En: Gonzalo DIAZ (ed.), Antropología Contemporánea. Intersecciones, encuentros y reflexiones desde el Sur Sur. Temuco: Ed. Universidad Católica de Temuco. pp. 83-103.

BRIONES, Claudia 2008. Cartografías argentinas: Políticas indigenistas y formaciones provinciales de alteridad. Buenos Aires: Antropofagia.

BUSTAMANTE, Javiera. 2016. "Procesos de activación y patrimonialización de sitios de memoria en Chile. 1990 al presente”. Aletheia, 7(13): 1-17.

BUTLER, Judith. 2010. Cuerpos que importan. Sobre los límites materiales y discursivos del "sexo". Buenos Aires: Paidós.

BUTLER, Judith; ATHANASIOU, Athena . 2017. Desposesión: Lo performativo en lo político. Buenos Aires: Editora Eterna Cadencia.

CALDEIRA, Teresa. 2015. "Social movements, cultural production, and protests: São Paulo’s shifting political landscape". Current Anthropology, 56(11): 126-136.

CALQUIN, Claudia; GONZALVEZ, Herminia (ed.). 2018. Epistemologias feministas desde el sur. Aportes, tensiones y perspectivas. Santiago: RIL Editores.

CAMPOS, Luis; DE LA MAZA, Francisca. 2019. "Los pueblos indígenas y afrodescendientes frente a la nueva Constitución”. En: Latercera.com Disponible en: https:/www.latercera.com/opinion/noticia/los-pueblosindigenas-afrodescendientes-frente-la-nueva-constitucion/925925/

CANCINO, Ronaldo; MORALES, Roberto. 2003. "La Antropología desbordada: Las huellas y marcas del hacer Antropología en el territorio Mapuche”. En: Nicolas Richard (ed.), Movimiento de campo: En torno a cuatro fronteras de la Antropología en Chile. Guatemala: Ediciones ICAPI. pp. 91-107.

CANDAU, Jöel ; HAMEAU, Philippe. 2004. “Cicatrices murales” En: J. Candau y H. Hameau (ed.), Le Monde Alpin et Rhodanien: Revue Régionale d'Ethnologie, 1:7-11.

CASTRO, Milka. 2014. “A Sesenta Años De La Antropología En Chile”. Revista Antropologías del Sur: Trayectorias Latinoamericanas de la Antropología, 1: 43-64. 
CEPAL. 2017. Estudio Económico de América Latina y el Caribe 2017: la dinámica del ciclo económico actual y los desafíos de política para dinamizar la inversión y el crecimiento. Santiago.

COLEGIO DE ANTROPÓLOGOS Y ANTROPÓLOGAS de Chile, A.G. Directorio Nacional. 25/10/2019.

Declaración Pública, Santiago, Temuco, Puerto Montt.

DANOWSKI, Deborah; VIVEIROS DE CASTRO, Eduardo. 2019. Hay Mundo Por Venir. Ensayo Sobre Los Miedos y Los Fines. Buenos Aires: Caja Negra.

DE LA CADENA, Marisol. 2015. Earth Beings. Ecologies of Practice Across Andean Worlds. London: Duke University Press.

DE MUNTER, Koen. 2016. "Ontología relacional y cosmopraxis, desde los andes: visitar y conmemorar entre familias aymara”. Chungará (Arica) 48(4): 629-644.

DURAN, Lucía. 2021. "Estallido social: Espacios y monumentos insurrectos de octubre". Revista Corpus. Archivos Virtuales De La Alteridad Americana, vol $11 ; \mathrm{n}^{\circ} 1$, paginas 1- 17. jul - dic.

ESCOBAR, Arturo. 2015. "Territorios de diferencia: la ontología política de los 'derechos al territorio”. Cuadernos de Antropología Social, 41: 25-38.

ESPINOZA, Claudio. 2014. "Presentación”. Revista Antropologías del Sur: Trayectorias Latinoamericanas de la Antropología, 1: 11-14

GIGLIA, Angela; GARMA, Carlos; DE TERESA, Ana Paula (comps.). 2007. ¿Adónde va la antropología? México: Universidad Autónoma Metropolitana-Iztapalapa/Juan Pablos. Biblioteca de Alteridades 7. Grandes Temas de la Antropología.

GONZÁLEZ, Raúl; MÁRQUEZ, Francisca. 2019. "Chile: de los subterráneos al protagonismo, ¿ocaso del modelo neoliberal?”. Revista Realidad Económica, 326: páginas 1-7. Buenos Aires: Instituto Argentino Para El Desarrollo Económico (IADE).

GUIZARDI, Menara; GONZÁLVEZ, Herminia. 2021. "Migraciones, cuidados y género: panoramas del debate en Chile”. En: D. Margarit; W. Imilan; J. Moraga (eds.), Investigando las migraciones en Chile. Campos interdisciplinarios actuales. Santiago: Ed. LOM.

GUIZARDI, Menara; GONZÁLVEZ, Herminia; STEFONI, Carolina. 2018. "De feminismos y movilidades. Debates críticos sobre migraciones y género en América Latina (1980-2018)”. Rev. RUMBOS TS, XIII(18): $37-66$.

GRAMSCI, Antonio. 2013. Cartas desde la cárcel. Buenos Aires: Ed.Losada. Biblioteca de Obras Maestras del Pensamiento.

GUNDERMANN, Hans; GONZÁLEZ, Héctor. 2009. "Sujetos sociales andinos, Antropología y antropólogos en Chile". Alpha, 29: 105-22.

HALBWACHS, Maurice. 2004. La memoria colectiva. Zaragoza: PUZ.

IBARRA, M. Ignacia; RIQUELME, Wladimir. 2019. "Sentipensar mapuche con las aguas del Huenehue: Hacia una ecología política y una antropología por demanda". Polis. Revista Latinoamericana, 54: 56-74.

INDH - Instituto Nacional de Derechos Humanos. 2020. "Información constatada por el INDH al 31-01-2020". Disponible en: https:/|www.indh.cl/

KROTZ, Esteban. 1993. "La producción de la antropología en el Sur: Características, Perspectivas, Interrogantes". Alteridades, 3(6): 5-11.

KROTZ, Esteban. 2008. “Antropologías segundas: enfoques para su definición y estudio”. En: José Eduardo Zárate Hernández (ed.), Presencia de José Lameiras en la antropología mexicana. Zamora: El Colegio de Michoacán. pp. 41-52. 
KROTZ, Esteban. 2018. "No se debe hablar en América Latina de una situación postcolonial sino de la tarea pendiente de de(s)colonización”. Plural. Antropologías desde América latina y el Caribe, 1(1): enero-junio. Recuperado a partir de https://asociacionlatinoamericanadeantropologia.net/revistas/index.php/plural/ article/view/24

LE BERT, Juan; SOTO, Maximiliano. 2021. "Inscripciones callejeras en tiempo de malestar: un análisis etnosemiótico de imágenes del estallido social en Chile Sur y Tiempo". Revista de Historia de América, 3: 66-85.

LINDSKOUG, Henrik et al. 2020. "Arqueología Contemporánea y Manifestaciones en Temuco, Chile: Conflictos, Violencia y Transformaciones del Espacio Urbano y la Materialidad". En: Simposio Conflicto, Materialidad Y Emociones: Contribuciones Desde La Antropología Latinoamericana. Coord. M. Jimeno, A. Góngora, A. M. Forero. VI Congreso de la Asociación Latinoamericana de Antropología: Desafíos Emergentes. Antropologías desde América y El Caribe. Montevideo, 24 -27 noviembre. Mimeo.

LOPEZ, Loreto. 2020. "Políticas de memoria para una nueva hegemonía cultural basada en el respeto por los derechos humanos". PERIFéRICA Revista para el análisis de la cultura y el territorio, vol $3 \mathrm{~N}^{\circ} 21: 278-285$.

MARIMAN, Pablo; AYLWIN, José. 2008. "Las identidades territoriales mapuche y el Estado chileno: conflicto interétnico en un contexto de globalización”. En: X. Leyva, A. Burguete y Sh. Speed (coord.), Gobernar (en) la diversidad: experiencias indígenas desde América Latina. Hacia la investigación de co-labor. México: Ciesas - Flacso.

MÁRQUEZ, Francisca; SKEWES, Juan Carlos. 2018. “Chile. Anthropology in.”. En: Hilary Callan (ed.), The International Encyclopedia of Anthropology. NY: John Wiley \& Sons Ltd. Published

MÁRQUEZ, Francisca. 2021. "Monumentos en Latinoamérica: Entre la épica patria y la insurrección”, Corpus [En línea], 11(1). Disponible en: http://journals.openedition.org/corpusarchivos/4505 MÁRQUEZ, Francisca et al. 2020. "Paisaje de la Protesta en Plaza Dignidad de Santiago, Chile". Revista Chilena de Antropología, 42: 112-145.

MÁRQUEZ, Francisca. 2020. "Anthropology and Chile's Estallido Social”. American Anthropologist, 122(2): 666-687. Disponible en: https://anthrosource.onlinelibrary.wiley.com/doi/full/10.1111/aman.13431

OSORIO, Catalina. 2021. La danza como herramienta de resistencia política. Estallido Social, Santiago de Chile.

Artículo científico para optar al título profesional de Antropóloga. Departamento de Antropología, Universidad Alberto Hurtado.

PALMA, Cristóbal; PIÑA, Leonardo. 2019. "Al ministro le falta calle". Etnografías de la revuelta. Disponible en: https://etnografiasdelarevuelta.blogspot.com/2019/11/al-ministro-le-falta-calle.html

PAVEZ, Jorge. 2015. Laboratorios etnográficos. Los archivos de la antropología en Chile (1880-1980). Santiago: Ediciones Universidad Alberto Hurtado.

PÉREZ, Miguel. 2018. "Toward a life with dignity: Housing struggles and new political horizons in urban Chile". American Ethnologist, 45(4): 508-520.

RANCIERE, Jacques. 2010. El espectador emancipado. Buenos Aires: Bordes Manantial.

RESTREPO, Eduardo. 2020, “Hacer Antropología desde América Latina hoy”. En: Gonzalo Diaz (ed.), Antropología Contemporánea. Intersecciones, encuentros y reflexiones desde el Sur Sur. Temuco: Ed.

Universidad Católica de Temuco. pp. 147-165.

RESTREPO, Eduardo. 2012. "Antropologías disidentes". Cuadernos de Antropología Social, 3: 55-69 RICHARD, Nelly. 2007. Figuras de la memoria: Arte y pensamiento crítico. Buenos Aires: Siglo XXI Editores. RIVERA-CUSICANQUI, Silvia. 2013. Un Mundo Ch'ixi es Posible: Ensayos Desde un Presente en Crisis. Buenos Aires: Tinta de Limón Ediciones.

RUIZ-TAGLE, Javier. 2019. Poniendo las cosas en contexto. Disponible en: https://coes.cl/opinion-poniendo-lascosas-en-contexto-ii/ 
SADLER, Michelle; ACUÑA M., Elena. 2003. "Traslaciones y aproximaciones: Desarrollo de la Antropología de género". En: Nicolas Richard (ed.), Movimiento de campo: En torno a cuatro fronteras de la Antropología en Chile. Guatemala: Ediciones ICAPI. pp. 211-223.

SANDOVAL, Pablo. 2021. "Sobre las Antropologías desde el Sur y otras cuestiones urgentes". PLURAL, 7: páginas 41 - 52 (Enero - Junio).

SEGATO, Rita Laura. 2007. Las Nación y sus Otros. raza, etnicidad y diversidad religiosa en tiempos de políticas de la identidad. Buenos Aires: Prometeo Libros

SEGATO, Rita Laura. 2016. La guerra contra las mujeres. Madrid: Traficantes de Sueños.

SKEWES, Juan Carlos. 2004. "La enseñanza de la Antropología en Chile”. Anales del Instituto de Chile, 24(2): 357-400.

SKEWES, Juan Carlos; QUIROZ, Rodolfo. 2020. "Civilización y Barbarie. Lecciones del Negro Matapacos". Raza Cósmica. Revista de Cultura y Política Latinoamericana. Disponible en: https:|/razacomica.cl/ sitio/2020/01/06/lecciones-del-negro-matapacos/

SKEWES, Juan Carlos 2019. Regeneración de la vida en la era del capitalismo. Otras huellas en los bosques nativos del centro y sur Chile. Santiago: Ocho Libro.

STENGERS, Isabelle. 2014. "La propuesta cosmopolítica". Pléyade , 14: 17-41.

TAYLOR, Diana. 2015. El archivo y el repertorio. La memoria cultural performática en las Américas. Santiago: Ed. Universidad Alberto Hurtado. Colección Antropología.

URZÚA, Sergio. 2019. "Aportes a una etnografía de los movimientos feministas: recursos expresivos en las marchas \#Ni una menos y \#8M en Santiago de Chile”. Antípoda. Revista de Antropología y Arqueología, 35: 115-124. Disponible en: https://doi.org/10.7440/antipoda35.2019.06

VALENZUELA, Mariana. 2019. "La marcha más grande de Chile”. En: Kathya Araujo (ed.), Hilos Tensados. Para leer el octubre chileno. Santiago: Usach. pp. 315-322.

VEKEMANS, Roger; GIUSTI, Jorge; SILVA, Ismael. 1970. "Marginalidad, Promoción Popular e Integración Latinoamericana”. Cuadernos de Discusión, 4. Santiago: DESAL - Centro para el Desarrollo Económico y Social de América Latina.

\section{Francisca Márquez}

Departamento de Antropología, Universidad Alberto Hurtado, Chile

https://orcid.org/o000-0002-9479-0001

Email: fmarquezb@gmail.com 